\title{
Mereología, teoría del conocimiento y metafísica de Ortega como fundamento de la Antropología metafísica de Julián Marías
}

\author{
Francesco De Nigris ${ }^{1}$
}

Recibido: 10 de diciembre de 2015 / Aceptado: 21 de julio de 2017

Resumen. Para una mejor comprensión de la Antropología metafísica de Julián Marías es menester remontarnos a la mereología, a la teoría del conocimiento y a la metafísica de Ortega, sobre todo para aclarar qué significan "estructura", "sistema", "órgano" y "función”. La razón vital es proyecto personal en tanto que apertura sistemática a su circunstancia cuya estructura unitaria, empírica, estructural, es "el hombre".

Palabras clave: Proyecto personal; estructura; sistema; función; órgano.

[en] Ortega's Mereology, Theory of Knowledge and Metaphysic as the Foundation of Julián Marías' Metaphysical Anthropology

Abstract. For a better understanding of Julián Marías' Metaphysic Antropology, it is recommendable going back to the Ortega's mereology, epistemology and metaphysic, especially in order to clarify the meaning of "structure", "system", "organ" and "function". The vital reason is personal project as the systematic openness to its circumstance, whose unitary, empirical and structural structure is "man".

Keywords: Personal project; structure; system; function; organ.

Sumario.1. Introducción; 2. Estructura, sistema, función, órgano y sentido. Una reconstrucción de la mereología inspirada en las Meditaciones del Quijote y guiada por la Antropología Metafisica; 3. Mereología, teoría del conocimiento y metafísica en la génesis de la razón vital; 4. Proyecto como apertura sistemática. La razón vital es personal; 5. El hombre como nostridad y como "estructura empírica"; 6. Recapitulación y conclusiones; 7. Referencias bibliográficas.

Cómo citar: De Nigris, F. (2018): "Mereología, teoría del conocimiento y metafísica de Ortega como fundamento de la Antropología metafísica de Julián Marías", en Revista Anales del Seminario de Historia de la Filosofía 35 (1), 205-232. 


\section{Introducción}

En el año 1970 sale a la luz en la Editorial Revista de Occidente la obra del filósofo español Julián Marías titulada Antropología metafísica. En ella, como cuenta el autor en un revelador prólogo a su nueva edición en Alianza Editorial, de 1983, se alcanza un nivel filosófico decisivo dentro de su pensamiento, implícito en todos sus escritos anteriores y desde el cual se ha hecho posible, según sus mismas palabras, «una interpretación rigurosamente personal y a la vez empírica del hombre» ${ }^{2}$. En el presente escrito intentaré mostrar el significado más preciso de estos dos adjetivos que el autor enérgicamente subraya, y cuya peculiar conexión lleva la teoría antropológica de Marías, como indica el título de su obra, a ser metafísica.

La persecución más rigurosa de tal propósito, sin embargo, nos obliga a dilucidar los supuestos fundamentales de esta doctrina en vista de la filosofía más profunda de Ortega. En efecto, el carácter "empírico" de la idea de hombre que esgrime la antropología de Marías, como él mismo indica en su obra, se refiere a un eslabón de realidad estructural, llamado "estructura empírica de la vida humana", que entreteje el nivel más abstracto de la estructura analítica de la vida humana que descubre Ortega y la realidad concreta que es, siempre, "mi vida". Eso obliga, en primer lugar, a aclarar una noción sobremanera problemática, la de "estructura", que Marías, como indica en su obra, adopta inspirándose en la mereología de su maestro, concretamente en las Meditaciones del Quijote. Esta obra, por tanto, cobrará el mayor protagonismo a lo largo del presente trabajo, en que comprobaremos que dicha mereología, en realidad, no ha sido nunca recontruida en la literatura filosófica orteguiana, lo que ha favorecido insistentes interpretaciones fenomenológicas. En las páginas que siguen, entonces, en primer lugar, se ofrecerá una personal y concentrada exposición de los conceptos de estructura, sistema, función, órgano y sentido; en segundo lugar, comprobaremos que sus ancestros teóricos se remontan incluso a Adán en el paraíso. Entonces, se comprobará que la mereología de Ortega está estrictamente vinculada a una epistemología donde el concepto tiene una función esquemática ilimitada, es decir, que coincide en última instancia con el "percepto" porque es función de la perspectiva proyectiva de la vida individual como "realidad radical". Por este camino, finalmente, podremos comprender la necesidad teórica de la estructura empírica de la vida humana averiguando que la razón vital es proyecto personal; en otras palabras: la vida como proyecto significa apertura sistemática que reordena o reabsorbe sistemáticamente las estructuras de elementos que radican en ella, en vista de una única estructura llamada "el hombre", que es el término medio necesario de la vida interindividual. Y esta, finalmente, se revelará como encuentro creador entre yo y tú, de suerte que cada proyecto individual implica a la vez que complica "el hombre". La unidad de las estructuras antropológicas -se concluirá- es necesaria en tanto que funcional para la realización de la vocación proyectiva personal de la vida, pero sus contenidos estructurales, a pesar de su relativa permanencia, cambian o, en todo caso, siempre pueden imaginarse diferentes de lo que van siendo. La estructura social o la estructura corporal son claros ejemplos estructurales de esa variación. 
2. Estructura, sistema, función, órgano y sentido. Una reconstrucción de la mereología inspirada en las Meditaciones del Quijote y guiada por la Antropología metafísica

En el Prólogo de 1983 a la edición de Alianza de la Antropología metafísica (1970), encontramos un esencial indicio de lo que Julián Marías entiende por "estructura". Allí recuerda que al haber tenido en cuenta la escueta pero esencial definición que dio Ortega de ese término en las Meditaciones del Quijote (1914), pudo preservarse de las desfiguraciones semánticas que fue padeciendo a lo largo del siglo XX. Estructura significa, al pronto, «elementos + orden»" ${ }^{3}$. No se trata, por tanto, de elementos aislados a los que les sobreviene una conexión. "Soledad", "aislamiento" son conceptos que denotan retracción de un elemento respecto de otros, y, por ello, de por sí, alusión al conjunto que forman, a su "estructura". Dicho esto, no hay que perder de vista las dos proposiciones fundamentales, de recíproca validez, con las que Marías introduce la definición de Ortega: «que no toda estructura es sistemática» y que «el sistema no se agota en ser estructura» ${ }^{4}$.

Para empezar a desplegar la compleja teoría que entrañan estos dos anexos, acudimos a sendos ejemplos. Tomemos, en primer lugar, el juego del ajedrez. Desde el punto de vista de dos contrincantes, el movimiento que uno ejerce sobre una pieza produce en el otro un replanteamiento, de cara a su propio movimiento, que afecta a todas las piezas en juego. En otras palabras, los elementos ordenados que cubren el tablero son una estructura según la cual cada elemento implica todos los demás a la vez que, moviéndose, los co-implica o complica. Marías suele llamar a esta relación entre todos y partes "sistemática", y a la realidad que la produce, "sistema". Sin embargo, dada esta concepción, ¿es admisible afirmar, como lo hace especificadamente la primera de las dos proposiciones antedichas, que existen estructuras que no son sistemáticas, especialmente cuando hemos dado por supuesto con Ortega que una cosa sola no existe, sino que remite inevitablemente a otras, en intrínseca conexión? Pasemos al segundo ejemplo; con él podremos alcanzar algo más de claridad sobre un asunto cuya problematicidad nos acompañará hasta el final de este escrito.

Imaginémonos ante una estantería, con la tarea de colocar un conjunto de libros alfabéticamente en ella. Una vez terminada esta labor, quitemos uno de los ejemplares y preguntémonos: ¿habiendo sustraído del conjunto un elemento, cambia el orden alfabético con el cual los demás siguen hallándose en la estantería? La respuesta, evidentemente, es "no", si bien menos evidente es su razón. Esta hay que buscarla en el principio que ordena, configura o da "un fin" al conjunto de nuestros elementos. El principio del ajedrez, según hemos señalado, es sistemático porque implica en cada elemento el todo que, a su vez, en el movimiento de cada uno se complica. El principio alfabético, sin embargo, no parece otorgar al conjunto un fin sistemático: hay un orden, mas los elementos, con tal que se hayan definido como aptos para la tarea de ordenación estructural -la alfabetización-, no son singularmente imprescindibles para que ese mismo orden se mantenga. La conclusión que hallaremos es la siguiente:

\footnotetext{
J. Ortega y Gasset: Meditaciones del Quijote, Obras Completas, I, Taurus, Madrid, 2004, p.350 [desde ahora en adelante se hará referencia al título de la obra y al tomo de la edición canónica de Taurus, volúmenes I-X, 2004-2010].

$4 \quad$ J. Marías: Antropología Metafísica, p.11.
} 
el orden de una estructura es cada vez más sistemático en la medida en que su principio de ordenación reconoce a los elementos su mayor singularidad respecto del conjunto, hasta el límite que al conjunto le va la plena realidad del elemento singular, que, de esta suerte, llega a serle imprescindible, es decir, "individual". Naturalmente, vale también lo contrario: que el conjunto que es la estructura, al que continuamente colabora el comportamiento de cada elemento, es simultáneamente imprescindible, tal como va formándose, a cada uno de ellos.

Un principio alfabético de ordenación, en efecto, no considera los libros más que por las letras de los nombres de sus autores o, si queremos, de sus títulos, por lo tanto cualquier libro, incluso solo la mera potencialidad de la existencia de libros, permite concebir la estructura que es una librería; mientras que respecto del ajedrez, el principio que corresponde a su juego divide cada pieza, por su figura y posición, en un elemento con una función sistemáticamente significativa respecto de las demás. Y la función significativa que adopta un elemento en vista del todo la llamaremos, como primera acepción suya genérica, su "sentido". Parece ser, entonces, que "una cosa" adquiere mayor sentido, o sencillamente realidad "sustancial", conforme aumenta su individuación en la sistematicidad de la estructura en que se halla ${ }^{5}$.

Ahora bien, este peculiar planteamiento nos invita a admitir, también, que dado el grado de sistematicidad de una estructura, cabe siempre pensar en otra más "ordenada" que la envuelve, es decir, que denuncia su "falta" de sistematicidad". Por supuesto, es concebible un principio de ordenación más sistemático que el alfabético; por ejemplo, el que añade a él -con un cierto orden de preferencia y coherencia ${ }^{7}-$ el año de publicación o la rama científica a que los tomos pertenecen, creando una estructura sistemáticamente más compleja porque extiende su consideración a otros aspectos de los elementos, individuándolos en mayor grado. Lo mismo, naturalmente, puede reclamarse respecto del ajedrez: en todo momento es concebible una relación aún más sistemática de la que pone en conexión cada pieza con el conjunto. Sin embargo, se dirá, y con razón, que entonces ya no tendríamos una colocación alfabética ni tampoco el juego del ajedrez, sino, respectivamente, otra catalogación u otro juego. Aquello a lo que apunta esta objeción -y Julián Marías ha insistido en ello ${ }^{8}$ es que una estructura tiene una razón de existir por su "función", es decir, por el fin o "para" al que su principio la destina o, respecto de ciertos sistemas, predestina.

5 Tal concepción, sin embargo, reforma implícitamente la categoría clásica de sustancia, que, como veremos en el apartado III, se disuelve semánticamente en la de relación.

6 Zubiri comprendió perspicazmente esta propiedad, y definió la respectividad de los elementos de un sistema de cara a su trabazón estructural interna y externa, es decir, respectivamente, en vista del orden de las notas internas y clausuradas en su sistema -"versión"- y del orden externo de las realidades sustantivas entre sí -"mundo"-. Cf. X. Zubiri: Sobre la esencia, Alianza Editorial, Sociedad de Estudios y Publicaciones, Madrid, 1985, pp.287, 288. (Abandona Zubiri los calificativos de interno y externo para la explicitación de la respectividad en su "Respectividad de lo real", REALITAS III-IV 1976-1979, Trabajos de Seminario Xavier Zubiri, Sociedad de estudios y Publicaciones, Madrid, 1979, pp. 23ss.)

7 "Coherencia" porque el principio tiene que contar con caracteres de los que no carezcan algunos ejemplares, de lo contrario quedaría roto el orden del conjunto.

8 Cf. J. Marías: Ortega. Circunstancia y vocación, Obras IX, Revista de Occidente, 1982, p.557. Función ha ido adquiriendo una acepción peculiar debido a la influencia de la matemática. En la medida en que se reduce el "por" a "causa" y el "para" a su "efecto" (lo que, en rigor, los reduce a identidad), la función, a pesar de su sistematicidad algorítmica sin solución de complejidad, está predestinada. "Sentido", sin embargo, solo en su acepción más lata, como conexión causal de los elementos, se identifica con función. Para su acepción más profunda, aparte de lo que podré decir en este escrito, véase F. de Nigris: "Ortega et la métaphysique", Revue Internationale de Philosophie, 1/2015, Vrin, Paris. 
El principio de una estructura, que podríamos llamar su "por", se denuncia en el "para" del conjunto en que los elementos han sido ordenados. Una acepción más precisa de sentido en cuanto función de cada elemento respecto de un todo, entonces, remite a su vez al sentido o función de la estructura misma: a su principio de ordenación que se manifiesta en su finalidad estructural. Y principio y fin de una estructura, de acuerdo con lo que hemos ya remarcado, se intensifican al tomarse en consideración las estructuras de sistematicidad superior que la implican, complicándose a su vez en ella.

Ahora bien, nuestra reiterada y decisiva observación acerca de la capacidad del hombre para "tomar en consideración" estructuras, para descubrir el sentido sistemático de sus elementos, incluso de cara a órdenes más complejos; en definitiva, para componer y descomponer a su sazón las cosas en su trato con ellas, introduce definitivamente a lo que ya estaba anunciándose a los más familiarizados con esta dimensión de la filosofía: que cualquier teoría de todos y partes o mereología, que se ha expresado a partir del siglo XVII con el nombre de ontología -en tanto que teoría de la "consistencia" del ser9-, no puede prescindir de una lógica que depende de una teoría del conocimiento, y que, en última instancia, se sostiene implícita o explícitamente en una metafísica. En la doctrina que acabamos de expresar en sus rasgos generales, en efecto, se reconocen con facilidad operaciones lógicas como la intensión y la extensión -según nomenclatura analítica-, si bien la composición "funcional" de las partes en términos de principio y fin, sus planos de realidad que remiten a ordenaciónes sistemáticas de "sentido", invitan a pensar en supuestos filosófico proprios, que es menester acotar si pretendemos alcanzar alguna claridad respecto del pensamiento de Marías. De hecho, solo determinando el puesto que ocupan en su doctrina la mereología y la epistemología, y la conexión de ambas en vista de una metafísica, podremos divisar el significado más preciso que adquieren las nociones de estructura y sistema. Con todo ello, finalmente, cumpliríamos con el propósito de introducirnos a la idea de que el hombre es «la estructura empírica de la vida humana».

\section{Mereología, teoría del conocimiento y metafísica en la génesis de la razón vital}

El punto de partida de Marías, como él mismo a menudo recuerda en Antropología Metafisica, son las Meditaciones del Quijote de su maestro. La reconstrucción que acabo de ofrecer delimita semánticamente las nociones de estructura, sistema, función, órgano y sentido. Con ellas se favorece la comprensión de cómo Ortega, planteando su mereología desde la noción de los conceptos y de las ideas como órganos, así como desde el pensamiento como función de la vida, fue penetrando en la perspectiva metafísica de la razón en que consiste la vida individual: sistema abierto de conexiones en que radica el sentido de "todo lo que hay", esto es, "realidad radical". El no haber recorrido este camino ha llevado algunos intérpretes a no detenerse ante una reiterada afirmación de Julián Marías acerca de la doctrina orteguiana: que el concepto de "circunstancia" -respecto, por ejemplo, del de

9 Cf., entre otros, J. Ortega y Gasset: Apuntes sobre el pensamiento, su teurgia y su demiurgia, VI, p.16ss; Historia como sistema, I, p.56, 60, 63, en su uso más maduro, La idea de principio en Leibniz. 
Umwelt de Husserl- es meramente "funcional"10. Tal afirmación, por otra parte, es inseparable de otra tan poco entendida como aquella: que el primer "yo" de la famosa fórmula orteguiana -"yo soy yo y mi circunstancia..." - significa mi persona como sinónimo de "mi vida", a la vez que el segundo "yo" apunta a su carácter proyectivo, en vista del cual la circunstancia funciona y se personaliza en mundo. Veremos que estas dos aseveraciones, sin embargo, no solo son decisivas para ganar la evidencia de la apertura sistemática de la razón vital, que es personal, sino, también, para

10 Cf. J. Marías: Ortega. Circunstancia y vocación, p. 498. En cuanto a la referencia crítica, cf. P. Cerezo Galán: La voluntad de Aventura. Aproximación critica al pensamiento de Ortega y Gasset, Ariel, Barcelona, 1984, p.219, 226. Estas serían aquí algunas de las tesis principales de la obra de Galán: que Ortega en las Meditaciones del Quijote explora la Lebenswelt de Husserl - concepto que sería, implícito si bien no terminológicamente explícito, en Ideen I- como correlato mundano de una idea "ejecutiva" de la intencionalidad -idea que, según Galán, derivaría de la crítica de Natorp a Husserl (p.213)-; que en tal "circuito" de análisis intencional reflexivo sobre la vivencia intencional ejecutiva del mundo se alcanzaría la alétheia, la continua revelación de "ideas" para la seguridad del hombre, es decir, "la cultura"; que la intencionalidad ejecutiva, a diferencia del cogito cartesiano, vincula el yo de la conciencia a la circunstancia, tratándose, por lo tanto, de un yo "espontáneo" que se hace cada vez más "autoconsciente" -y, por ello, menos "gregario" y más "personal"- mediante la reflexión, la cultura (pp.31, 32, 313); que la alétheia es preanunciada por el método fenomenológico (pp.320ss), donde mención e intuición, con epistemológica en epokhé, conducen a una lógica representacionista y descriptiva (pp.250,252); que Ortega no abandona la epokhé incluso hasta la altura de ¿Qué es filosofía? (p.299), y que la reducción eidética no será nunca descartada como expediente teórico del filósofo español (p.215), el cual, finalmente, a partir de los años 30, apresuradamente y mediante un ejercicio de "enmascaramiento" terminológico, intentará reconducir su famosa fórmula de 1914 a posturas heideggerianas para ostentar primigenia originalidad (p.319), aseverando que el primer "yo" de su fórmula es "vida" como fenómeno metafísico originario de "hallarme en el mundo". Mereciendo estas ideas un análisis más detenido, veremos en lo que sigue, por lo menos, que se desvían del genuino concepto orteguiano de alétheia, el cual apunta a una mereología donde sentido o lógos es conexión, virtualidad, es decir, en modo alguno reflexión y descripción de la vida intencional ejecutiva, transcendental constituyente de la conciencia egóica mediante el sistema de reducciones. Si realmente el concepto de "ejecutividad" que Ortega utilizó para demarcar los límites de la reflexión fenomenológica -en Sobre el concepto de sensación de 1913 o en El ensayo a manera de Prólogo de 1914 - procediese de la intencionalidad husserliana en su versión mundana, "natural", que vive y discurre en inalienable primera persona -ich rede-, ese mismo uso denunciaría, inevitablemente, como a su modo expresó Natorp, una desvinculación inmediata del método fenomenológico y, en el caso de Ortega, como de hecho ocurre, un completo replanteamiento del sentido del principal concepto de todo el idealismo: "yo". En efecto, apercibiéndose como "yo ejecutivo", continuamente encontrándose así en "mi vida", Ortega se desmarca de la apercepción fenomenológica como la producción del espectador imparcial que busca captar, suspendiendo el mundo como horizonte de validez del ser, la vida activa y pasiva constituyente del ego transcendental. La evidencia de la ejecutividad de "mi yo", ante el cual "no podemos situarnos en postura utilitaria", porque "es todo en cuanto ejecutándose" (I, 667ss.) lleva a Ortega a interpretarlo como "forzosa libertad", y, por tanto, a entenderlo con la categoría de "programa", "proyecto", "pretensión", y la vida, por su parte, como "mi vida": como ese "quehacer" que "no está dado hecho" porque en él se hace, forzosa y continuamente, mi propio yo. No es menester ningún "círculo" de intencionalidad mundana reflexiva para que mi yo sea personalmente más consciente y menos gregario, porque yo ejecutivo significa para Ortega, previamente a cualquier reflexión, mi vida haciéndose personalmente: forzosa libertad de anticipar vocacionalmente quién voy a ser, es decir, «la reabsorción de la circunstancia como destino concreto del hombre» (Ibid. p.756). Por otra parte, el sistema de reducciones de la fenomenología de la conciencia intencional busca recuperar una lógica y una ontología puras -formal o material- para asegurar la verdad en su noción clásica como adaequatio. La consistencia y verdad de las estructuras circunstanciales, al contrario, como vamos a ver, remiten inevitablemente a mi "уо" como proyecto, cuya verdad es autenticidad. Sin esta última claridad, se estaría sustrayendo la fuente de sistematicidad -o reabsorción- de la "perspectiva", se pierde su originalidad mereológica (estructura, sistema, órgano, función, conexión...) y epistemológica (ideas y conceptos como órganos; concepto como percepto, alétheia y perspectiva; pensamiento como función...). Y solo mediante mi yo proyectivo, fuente de verdad como autenticidad, se entiende la concepción orteguiana del "pensamiento" como "saber a qué atenerse", es decir, como fuente interpretativa de certidumbres explícitas o implícitas (ideas y creencias) de mí en el mundo. Esta función del pensamiento no tiene ninguna cabida en la doctrina husserliana, ya que en ella el pensar -y aun el conocer- se deriva de la actividad constituyente de significación e impleción de la conciencia egóica, en que se gesta el ser y su modalización. 
introducirse metafísicamente a la estructura empírica que necesariamente emerge de ella y que Marías llama “el hombre".

Acabamos de recordar que Ortega afirma que una cosa sola es un contrasentido, ya que el dar con una significa para el hombre afirmar siempre otras. Si nuestro campo de visión aparece como una superficie, lo real no se agota de ningún modo en ella. Tras el aparente protagonismo de lo relevante, tras lo que de inmediato vemos del "mundo", se esconde un "trasmundo" que dilata y posibilita lo superficial. Para explicar esta idea Ortega en su primer libro multiplica los ejemplos. Empieza con aquel célebre del bosque que inicia el primer apartado de la "Meditación preliminar"; sigue en el apartado dos - "Profundidad y superficie"- con otro conocido tema de análisis: una naranja. A ellos se añade en el apartado cuatro -“Trasmundos"- un azul, y finalmente en el apartado nueve - "Las cosas y su sentido"- toma en consideración un fresno. El objetivo teórico inmediato es el mismo: la realidad es profundidad y superficie, latencia y patencia, es decir, orden, de lo contrario sus elementos no tendrían conexión o sentido (lógos).

Profundidad es un género que tiene muchas especies: un bosque se nos presenta en cercanía o en lejanía espacial. Oteamos una exigua arboleda sin sospechar la extensión que encubre y que revela finalmente el bosque al internarnos en ella, entre sus troncos y ramajes. Pero también puede resurgir el bosque desde nuestro pasado: una vez dejado atrás en el camino, perdido de vista, de repente se asoma en mis recuerdos reavivada su imagen por otras matas que me salen al encuentro. Se gana con ello una primera certeza: las cosas se estructuran de un modo u otro según nuestro trato con ellas. Su profundidad, sin embargo, no se limita a lo espacial y a lo temporal: encuentro en las cosas mis ideas. La naranja que veo es solo la mitad que puedo de ella percibir, mas pienso esa mitad con la idea de naranja que ya tengo. El azul de una prenda es desteñido porque lo veo a través de la idea de azul que fue o que desearía que fuera. La dilatación de la superficie mediante el acervo de ideas que tenemos de las cosas que en ella aparecen es llamada por Ortega "escorzo"11. Algo parecido en la tradición idealista, desde Leibniz y pasando por Kant, se ha asumido bajo la problemática noción de "apercepción". No pasa por la mente del filósofo español, sin embargo, justificar la estructuración de las sensaciones kantianamente, mediante la imaginación pura que produce determinaciones a priori de tiempo -esquemas-, categorizando el pensamiento de un yo que acompaña a todas sus representaciones, asegurando la unidad de la conciencia; ni se organizan los contenidos sensibles (hyle) en una conciencia interna del tiempo que, en protensión y retensión, favorece su asociación pasiva y, finalmente, actos intencionales, según terminología husserliana. La consideración de Ortega es ante todo metafísca: sin escorzo no habría ni profundidad ni relieve, ni latencia ni patencia, sino plena transparencia, esto es, "nada"12 ¿Pero qué relación podemos concretamente establecer entre las dimensiones "materiales" -espaciales, temporales, auditivas, táctiles...-y las intelectuales de la percepción?

Volvamos por un momento al pasaje del bosque de las Meditaciones, justo después de describir Ortega brillantemente el sonido del agua que corre y el grito de una oropéndola: «Tal es la presencia de estos nuevos sonidos, tales son como meras impresiones. Pero yo, al escucharlos, no me he detenido a describir-según aquí he hecho- su simple presencia. Sin necesidad de deliberar, apenas los oigo los envuelvo

Y el Quijote, "libro escorzo por excelencia", es "una selva ideal". Cf. Meditaciones del Quijote, I, 770.

Ibid. p.766. 
en un acto de interpretación ideal y los lanzo lejos de mí: los oigo como lejanos. Si me limito a recibirlas pasivamente en mi audición, estas dos parejas de sonidos son igualmente presentes y próximas. Pero la diferente calidad sonora de ambas parejas me incita a que las distancie, atribuyéndoles distinta calidad espacial. Soy yo, pues, por un acto mío, quien las mantiene en una distensión virtual: si este acto faltara, la distancia desaparecería y todo ocuparía indistintamente un solo plano. Toda esta profundidad de lontananza existe en virtud de mi colaboración, nace de una estructura de relaciones que mi mente interpone entre unas sensaciones y otras ${ }^{13}$. La realidad ejecutivamente vivida trasciende cualquier estrategia descriptiva. "Soy yo", "sin necesidad de deliberar", quien interpreta un sonido como lejano, distanciándolo de otro. "Acto", entonces, es el agere humano en que visión e idea se "funden", y el escorzo es su resultado: es «órgano de profundidad visual», es decir, de realidad: «en él hallamos un caso límite, donde la simple visión está fundida en un acto puramente intelectual» ${ }^{14}$.

Un ver pasivo, por lo tanto, no existe; sería la disolución del escorzo en el impresionismo de la pura materia: «Si no hubiera más que un ver pasivo quedaría el mundo reducido a un caos de puntos luminosos. Pero hay sobre el pasivo ver un ver activo, que interpreta viendo y ve interpretando; un ver que es mirar. Platón supo hallar para estas visiones que son miradas una palabra divina: las llamó ideas» ${ }^{15}$.

"Idea", al igual que "acto", reforma su semántica filosófica: es el aspecto en que se manifiesta toda cosa respecto de las demás, es decir, en todas las dimensiones perceptivas, donde el tiempo en que se exponen es la historia de sus perfiles. «El azul que tenemos delante lo vemos como habiendo sido otro azul más intenso y este mirar el color actual con el pasado, a través del que fue, es una visión activa que no existe para un espejo, es una idea. La decadencia o desvaído de un color es una cualidad nueva y virtual que le sobreviene, dotándole de una como profundidad temporal. Sin necesidad del discurso, en una visión única y momentánea, descubrimos el color y su historia, su hora de esplendor y su presente ruina ${ }^{16}$.

Una idea no es un espejo que pasivamente representa, sino visión en que se hallan las cosas en escorzo, con lo cual "sin necesidad del discurso" puede ser la idea una percepción ejemplar como "un azul" o "una naranja", al igual que puede expresarse con palabras infinitamente ricas de resonancias intelectuales como "naturaleza" o "Dios". En la medida en que la idea intelectualiza el escorzo, de hecho, cabría pensar en un "ideal" -igual de utópico que "la pura materia"- en que un "acto puramente intelectual", una intuición intelectual definitiva, resumiese todas las dimensiones "materiales" de la percepción, disolviéndolas en espíritu, que no es sino otra idea de nada ${ }^{17}$.

La idea, en definitiva, es el órgano de la cosa en la manifestación de su aspecto o "sentido", pero hay que evitar caer en el grave error de pensar que es el órgano lo

13 Ibid. 768.

$14 \quad$ Ibid. p.760.

15 Ibid. p.769. Como veremos en el tercer apartado, la pura materialidad, así como la absoluta intelectualización de lo real, son interpretaciones o "ficciones de totalidad", esto es, "ideas" en el sentido intelectual del término. Dichos extremos coinciden en las lógicas abstractas que a partir de la idea de la verdad como adecuación persiguen la máxima intensión o connotación de las palabras, en vista de un representacionismo atómico de lo real (véase Bertrand Russell). Cf. también Marías: Ortega. Circunstancia y vocación, p.560ss.

16 Ibid. Cotéjese este argumento, así como el entero presente apartado, con "Teoría de la realidad", en particular modo su sección "La estructura de la realidad" en J. Marías: Ortega. Circunstancia y vocación, p.546ss.

17 Cf. Ibid. p.770. 
que fabrica su función. Con ello se debería admitir -so pena un regreso al infinitouna función originaria, "racional", asignada a cada órgano, al modo de los esquemas kantianos o -si no se resuelve la relación entre intuición y significación ${ }^{18}-$ de las correlaciones noéticos-noemáticas husserlianas, anquilosándose, de esta suerte, la infinita plasticidad de los aspectos de las cosas en su recíproco perfilarse. La idea es inseparable de la cosa: funcionando esta, aquella se hace órgano. La cosa "martillo" -nunca hay que olvidar el famoso ejemplo- se constituye en tanto que «abstracción de sus martillazos» ${ }^{19}$.

Finalmente, a raíz de tal radical funcionalismo, una nueva conexión de ideas que se revela de repente a la mirada del hombre, como una "iluminación subitánea" que lo invade de entusiasmo y estupor, es lo que el filósofo español entiende por "verdad", inspirándose -al igual que harán otros pensadores- en la etimología originaria del término alétheia, cuyo significado se trasladaría sucesivamente al de apocalipsis ${ }^{20}$.

Ahora bien, dado el valor funcional de las ideas, es un error imperdonable que se las utilice para intentar acotar definitivamente un escorzo, como los egipcios que veían en el Valle del Nilo "lo mejor del mundo"21. «No existen más que partes en realidad; el todo es la abstracción de las partes y necesita de ellas. Del mismo modo no puede haber algo mejor sino donde hay otras cosas buenas $\rangle^{22}$. Este vicio de aislar el todo de las partes, de no comprenderlo a su vez funcionalmente como una parte de otro conjunto ulterior que lo ordena otorgándole valor ulterior, lleva al fenómeno que Ortega definirá "pensamiento confundente". En las Meditaciones, cuando afecta la disposición del hombre hacia la cultura, produce su "hieratización". Esta es el mayor anquilosamiento que ejerce la mente sobre la idea, en tanto que, olvidándose de su génesis y de su destino instrumental, se torna en inamovible punto de llegada. Lo mismo puede decirse respecto de la vida ética: «El ideal sólo es fecundo -entiéndase moralmente fecundo- cuando se hace entrar todo en él. Es un trabajo de amor y no de exclusión $»^{23}$.

Finalmente, dado el carácter epistemológicamente radical de las ideas, "cultura" no será nunca para Ortega un título añadido al curriculum de la humanidad, sino la misión irrevocable del hombre que de puramente natural no tiene nada, que vive interpretando y jerarquizando ideas en la medida en que descubren y responden a necesidades. «Toda necesidad, si se la potencia, llega a convertirse en un nuevo ámbito de cultura. Bueno fuera que el hombre se hallara siempre reducido a los

18 Desde el punto de vista de la razón vital, conviene aquí anticipar nuestras conclusiones para la mayor orientación del lector, la fuente de la síntesis, de la virtualidad infinita de lo real es "yo" como proyecto. "El yo" en Husserl, a pesar de que Lebenswelt llega a ser el horizonte noemático, no es "yo". Si así fuera configuraría la circunstancia en protensión y retensión, justificando su mundaneidad en su personalización, y, con esta, su índole vital. Sin embargo, la conciencia interna del tiempo nunca fue un instrumento explícito para la autoconstitución del ego, de allí que queda por justificar la intención significativa (Sinngebung) de la intuición intencional. Cf. F. de Nigris: "Intencionalidad, pasividad y autoconciencia en la fenomenología de Husserl", Ideas y Valores, LXIV, $\mathrm{n}^{\circ} 157$, Universidad Nacional de Colombia, abril de 2015.

$19 \quad$ Ibid. p.756.

$20 \quad$ Cf. Ibid. p.769.

21 Lo mismo que luego dirá del hombre provinciano respecto de su provincia, o del nuevo nacionalismo no incluyente respecto de su "nación" - a diferencia del nacionalismo moderno que buscaba contagiar y dejarse influir de su entorno para agrandar su historia-; o de la cultura especializada que comete la barbarie de extralimitar su mirada a campos que requieren otro cultivo (la barbarie del especialismo). Véase sobre todo España Invertebrada y Las Rebelión de las masas.

22 Ibid. p.756.

23 Ibid. p.751. 
valores superiores descubiertos hasta aquí: ciencia y justicia, arte y religión. A su tiempo nacerá un Newton del placer y un Kant de las ambiciones ${ }^{24}$. Cultura por lo tanto es «una interpretación -esclarecimiento, explicación o exégesis- de la vida» ${ }^{25}$; sus ideas tienen sentido porque crean seguridad ante la necesidad, mientras que la vida erudita es abstracta ostentación de ideas, saber que no se sabe a sí mismo. Podemos así concluir que «El acto cultural es el especificadamente creador, aquel en que extraemos el logos de algo que todavía era insignificante (i-logico). La cultura adquirida sólo tiene valor como instrumento y arma de nuevas conquistas» ${ }^{26}$. Tal es "la vuelta táctica" de la que habla Ortega a continuación de esta última cita. Vivir es movimiento de ida y vuelta, utilizar las ideas para buscar sentido a lo que aparentemente no lo tiene, «salvar las apariencias», ganar apertura y dar valor a las menudencias, aclimatarlas en nuevos parajes de sentido. Y ese esfuerzo generoso, pulcro y necesario, en definitiva heróico, que busca crear ordenes que valoran las cosas para valorar la vida, es, para el filósofo español, lo que significa por lo pronto "amor".

Desde el comienzo de la estremecedora exhortación al lector -principalmente al lector español-que Ortega antepone a la "Meditación preliminar", se asoma la teoría del amor platónico, del amor intelectualis de Spinoza, la conexión sistemática de las mónadas de Leibniz. Son ecos que resuenan, sin embargo, con una voz original: amor es llevar a cada cosa «por el camino más corto a la plenitud de su significado» ${ }^{27}$. La falta de amor, "el pecado cordial", luego, es el pecado capital de la vida, el que invierte su misión de claridad.

Encontramos ya anunciado, en los primeros pasajes de las Meditaciones, el antepasado teórico del esquema mereológico que hemos trazado en el apartado anterior, paulatinamente acompañado de su dimensión epistemológica. Las cosas cobran relieve e identidad según lo que cada una alumbra en las demás: solo en la alusión, en el reflejo, en la estructura que se establece entre ellas se descubre su lógos o sentido. Alétheia no es revelación como presentación de una disposición que las cosas tienen "en sí", actualidad como demarcación sustancial de cada una, sino continuo escorzo en que cada cosa, desde la mera percepción sensible, es reflejo de las demás, es decir, aspecto, idea, y tanto que si forzáramos la atención en conocer una, ella no se agotaría nunca, sino se convertiría en centro virtual del universo, es decir, foco para la comprensión infinita de todo lo que hay; y la razón de ello ya la hemos visto: porque idea es órgano funcionando, sin límite previo a su instrumentalidad. «Una cosa no se puede fijar y confinar más que con otras. Si seguimos atendiendo a un objeto este se irá fijando más porque iremos hallando en él más reflejos y conexiones de las cosas circundantes. El ideal sería hacer de cada cosa centro del universo. Y esto es la profundidad de algo: lo que hay en ello de reflejo de lo demás, de alusión a lo demás. El reflejo es la forma más sensible de existencia virtual de una cosa en otra. El "sentido" de una cosa es la forma suprema de su coexistencia con las demás, es su dimensión de profundidad. No, no me basta con tener la materialidad de una cosa, necesito, además, conocer el "sentido" que tiene, es decir, la sombra mística que sobre ella vierte el resto del universo. Preguntémonos

\footnotetext{
Ibid. p.755.

Ibid.788.

Ibid. p. 756 .

Ibid. p.747.
} 
por el sentido de las cosas, o, lo que es lo mismo, hagamos, de cada una el centro virtual del mundo» ${ }^{28}$.

Pero la mereología de Ortega no va solo perfilando una teoría del conocimiento, sino algo más, metafísica: la realidad no es la materia de las cosas o el alma como contenedor de ellas ${ }^{29}$, sino punto de vista o virtualidad, es decir, "perspectiva". "¿Cuándo nos abriremos a la convicción de que el ser definitivo del mundo no es materia ni es alma, no es cosa alguna determinada, sino una perspectiva? Dios es la perspectiva y la jerarquía: el pecado de Satán fue un error de perspectiva ${ }^{30}$. Con "la perspectiva" gana máxima expresión la infinita plasticidad de las ideas: se supera toda ontología abstracta racionalista, se trasciende la concepción de la verdad como actualidad-adecuación en vista de la verdad como sentido, que es virtualidad-perspectiva, además se vincula la estética de las conexiones a la ética de la autenticidad del hombre como proyecto de amor. «La perspectiva se perfecciona por la multiplicidad de sus términos y la exactitud con que reaccionemos ante cada uno de sus rangos. La intuición de los valores superiores fecunda nuestro contacto con los mínimos, y el amor hacia lo próximo y menudo da en nuestro pecho realidad y eficacia a lo sublime. Para quien lo pequeño es nada, no es grande lo grande ${ }^{31}$.

Y es con el concepto riguroso de perspectiva, por lo tanto, que tenemos que volver sobre la cita anterior, en que nos hemos referido a la posibilidad ideal de hacer de cada cosa centro virtual del Universo. Ortega - es importante insistir en ello- no dice centro actual o definitivo del universo -postura racionalista-, sino "virtual", que es lo que confiere el carácter utópico a la idea de verdad como adecuación en su vertiente realista - cosas-almas- o idealista -conciencia-cosas-. En la medida en que mi vida es perspectiva, profundidad y superficie, nunca puede haber un lugar no virtual. Una perspectiva que generara una actualidad habría estrechado definitivamente su rango amoroso, allanando su horizonte, convirtiéndolo y convirtiéndose ella misma en nada. Cada cosa, nada más dar con ella, se nos ofrece generosa como centro virtual de comprensión del universo, es decir, se proyecta con nuestra mirada, se hace ob-yectum para reflejar a las demás: revelarlas u objetivarlas; siendo la vida, entonces, mundo: trama última en donde todos los hilos que conducen de cosa a cosa se anudan, desenlazan y vuelven a tejer. Y así cabría imaginar la visión divina extremando el ejercicio erótico de la proyección hasta la infinita creación de puntos de vista, y de puntos de vista que crean. «¿No es esto lo que hace el amor? Decir de un objeto que lo amamos y decir que es para nosotros centro del universo, lugar donde se anudan los hilos todos cuya trama es nuestra vida, nuestro mundo, ¿no son expresiones equivalentes? $\gg{ }^{32}$. A la respuesta resueltamente afirmativa que concede a esta pregunta, sigue una nueva referencia que recuerda pasajes del Banquete y del Fedro: «Platón ve en el eros un ímpetu que lleva a enlazar las cosas entre sí; es -dicefuerza unitiva y es pasión de la síntesis. Por esto, en su opinión, la filosofía, que busca el sentido de las cosas, va inducida por el "eros". La meditación es ejercicio erótico. El concepto es rito amoroso» ${ }^{33}$. A continuación, en el apartado nueve, empieza su teoría del concepto, que no podemos obviar para concluir nuestro sucinto recorrido.

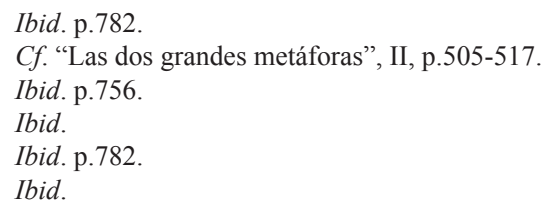


Con ella cobra definitiva identidad la acepción del término "idea", que hemos visto sorprendentemente oscilar entre la instrumentalidad del acto cultural voluntario y la espontaneidad ejecutiva, pre-verbal, de la percepción. Con el análisis del concepto, sin embargo, se acercará Ortega a comprender aún más que la semiótica de las cosas y la de las palabras son estructuras dinámicas funcionales a una misma razón: "mi vida" en tanto que "realidad radical", en cuanto razón última que es "raíz" de ordenación, sistematización o "radicación" de todo lo que hay. Cabe certificar, de momento, que estamos lejos de la Sinngebung husserliana: realidad es virtualidad, orden funcional para la perspectiva individual de mi vida cuya autenticidad es "amor": ampliación de su rango de aprehensión para que las conexiones que se revelan remitan a la necesidad de alumbrar el fondo que ocultan, siendo la cultura, entonces, capacidad de descubrir necesidades y saber a qué atenerse ante ellas, esto es, como vamos a ver, la función que en la vida explícita el "pensamiento".

La teoría orteguiana del concepto no es kantiana; no hay esquemas como determinaciones a priori del tiempo, de suerte que un puñado de categorías configura formaliter la sensibilidad e introduce el hombre en la "naturaleza". No se establece ninguna diferencia entre la imaginación productiva de esquemas y reproductivas de imágenes, no hay, en definitiva, para no alargar hasta el infinito la lista de salvedades, una diferencia entre la oriundez del concepto de la razón teórica y de la razón de la vida práctica. Tampoco hay una impleción que fija intuitivamente el concepto de la significación, con la cuestión abierta de justificar la intención de esta ${ }^{34}$. Encontramos en su primer libro, más bien, como algunos pronto han sabido reconocer ${ }^{35}$, la mayor espontaneidad del concepto que revela la ilimitada plasticidad de la percepción, hasta

34 Cf. supra nota 12.

35 En las Meditaciones del Quijote «Los conceptos se hallan, pues, más próximos a la vida de lo que la mayoría de los pensadores admite». J. Ferrater Mora: Ortega y Gasset, Editorial Seix Barral, Barcelona, 1958, p.56. Cf. con más detalle, A. Rodríguez Huéscar: Perspectiva y verdad, Revista de Occidente, Madrid, 1966, pp.74ss. Y como preciso complemento a todo lo que aquí se dirá, véase "Teoría del concepto" en J. Marías: Ortega. Circunstancia y Vocación, p.577 y el correspondiente comentario de Marías a la edición de Cátedra de las Meditaciones del Quijote (Madrid, 1984). Cerezo Galán opta, sin embargo, por considerar "la finalidad objetiva y alcance real" de la teoría orteguiana del concepto, interpretándola como una forma de intuición fenomenológica -"sea esta empírica o categorial, individual o esencial”-, recordando, luego, un pasaje de ¿Qué es filosofía? donde Ortega indica que el radicalismo filosófico no acepta «para sus frases otro modo de verdad que el de total evidencia fundado en intuiciones adecuadas» (pp.245, 246). De esta suerte, sin embargo, se sortea todo análisis del concepto como esquema, como límite instrumental o huella de las cosas funcionando. El objetivo de Ortega es liberar el concepto -al igual que la idea, según vimos- de una función preestablecida y a menudo atribuida a otra materia -psíquica- que, como otra cosa, la representaría. El esquema conceptual según Ortega - a diferencia del esquematismo kantiano- se configura funcionando la cosa misma; sus límites plásticos son los de las cosas en las que ya, de por sí, están vehiculadas por la codificación semántica -metafóricaevidentes en la etimología de las palabras, que responden a los proyectos vigentes de una sociedad. En cuanto a la recuperación del sentido clásico de la verdad como adaequatio, Ortega sin duda reconoce a la fenomenología -como es evidente en las Investigaciones psicológicas- un esfuerzo decisivo; mas desde la razón vital esta acepción de la verdad es solo una dimensión de ella. Lo intuitivamente adecuado es, siempre -como el martillo para dar martillazos- adecuación a mi ocupación, a mi proyecto: «su verdadero ser (se refiere Ortega en esta cita a "un pitillo") se reduce a lo que representa como tema de mi ocupación. No es por si subsistente, khoriotón, aparte de mi vivirlo, de mi actuar con él. Su ser es funcionante: su función en mi vida es un ser para -para que yo haga esto o lo otro con él». ¿Qué es filosofía?, VIII, p.384, 385. Páginas, estas, plenamente fieles a la mereología y epistemología de las Meditaciones del Quijote, a la vez que muestran un profundo conocimiento de Sein und Zeit de Heidegger, si bien, anticipan, como incluso sugieren las líneas sucesivas a nuestra cita ( $\ll \mathrm{Si}$, no obstante, como la filosofía tradicional, hablo del ser de las cosas como algo que éstas tienen por sí y aparte de su manipulación y servicio en mi vida, uso el sentido inveterado del concepto "ser"»), una divergencia del proyecto último del filósofo alemán: no interesa a Ortega - como a ninguno de sus discípulos-el sentido del ser, sino el sentido de la vida. Cf. F. de Nigris: "Ortega et la métaphysique”, op.cit. p.21. 
que el uno es el mismo "límite" de la otra, sin que sus conexiones respondan a un plan teórico previo (racionalismo). «El concepto no puede ser como una nueva cosa sutil destinada a suplantar las cosas materiales. La misión del concepto no estriba, pues, en desalojar la intuición, la impresión real. La razón no puede, no tiene que aspirar a sustituir la vida» ${ }^{36}$. La oposición entre concepto y percepto, normalmente adoptada desde el plano del pensamiento como acto de una facultad propia de la razón, es una abstracción. El concepto no está hecho de otra "materia", no pertenece a otro orden respecto de las cosas, pues su esquema «son los límites de la cosa, la caja lineal donde la materia, la substancia real de la cosa queda inscrita. Y estos límites, según se ha indicado, no significan más que la relación en que un objeto se halla respecto de los demás $\rangle^{37}$. La presencia de la cosa, que es un continuo ser vivida y, por tanto, posibilidad intrínseca de pasar de la superficie al fondo de nuestra perspectiva, hasta desaparecer en un cambio completo de escorzo, significa dejar un "esquema" de sí misma que no es "otra cosa", sino literalmente su concepto, con el que la cosa se afirma funcionalmente respecto de las demás. "Esquema" es la huella en que ha quedado inscrita la cosa respecto de todas las demás que sistemáticamente la han individuado en cada una de sus manifestaciones espontáneas. «Si de un mosaico arrancamos uno de sus trozos, nos queda el perfil de éste en forma de hueco, limitado por los trozos confinantes. Del mismo modo el concepto expresa el lugar ideal, el ideal hueco que corresponde a cada cosa dentro del sistema de las realidades. Sin el concepto, no sabríamos bien dónde empieza ni dónde acaba una cosa; es decir, las cosas como impresiones son fugaces, huideras, se nos van de entre las manos, no las poseemos» ${ }^{38}$. No son las palabras aquello que en principio pone coordenadas a las cosas; estas, funcionando, se hacen su hueco en la vida; forjan esquemas que transcienden toda percepción fáctica de ellas. Los esquemas aluden a las conexiones posibles de las cosas, son la virtualidad o posibilidad en que estas se escorzan; son, en definitiva, los conceptos en que la percepción se revela intrínsecamente como apercepción. Y las cosas, finalmente, cobran voz en las palabras, que guardan sus conceptos y las liberan para que, funcionando, sorprendan y reformen esos mismos conceptos establecidos verbalmente ${ }^{39}$. Se concluye, así, que palabras y cosas no difieren en "materia": son estructuras de la vida, funcionales a su proyecto ${ }^{40}$. «Si devolvemos a la palabra "percepción" su valor etimológico -donde se alude a coger, apresar- el concepto será el verdadero instrumento u órgano de la percepción y apresamiento de las cosas. Agota, pues, su misión y su esencia, con ser no una nueva cosa, sino un órgano o aparato para la posesión de las cosas $\rangle^{41}$.

Si volvemos ahora a las ideas, ¿qué relación tienen con los conceptos? Como hemos visto, y si queremos retomar nuestro marco de comparación, no son ellas síntesis de conceptos que la razón -como facultad general- formula para regularse

Ibid. p.784.

Ibid.

Ibid.

39 «La cosa que ha de ser aprehendida ejerce una modificación sobre el concepto para exigirle que se adapte más rigurosamente a ella, y el concepto recupera así, con el reconocimiento de su mero carácter instrumental, la plenitud de su eficacia». J. Marías: Introducción a la filosofia, Revista de Occidente, Obras II, Madrid, 1982, p. 173.

40 La vinculación orteguiana entre epistemología y mereología recuerda la Zuhandenheit y Vorhandenheit de Heidegger, si bien el funcionalismo de Ortega, como hemos anticipado y veremos mejor, está vinculado a una idea personal de proyecto.

41 Meditaciones del Quijote, I, p. 785. 
a sí misma, en términos de postulados que definen su horizonte -teórico, práctico y aún teleológico-. Ni, pasando de Kant a Husserl, son focos sintéticos que se alumbran entre intuición y mención intencional, componiendo categorialmente regiones como partes de "la región radical" de la conciencia, determinando la idealidad de sus objetos. Las ideas son conceptos a todos los efectos: estructuran lo real y desvelan conexiones, son órganos al servicio de la alétheia o apocalipsis. «Cada nuevo concepto es un nuevo órgano que se abre en nosotros sobre una porción del mundo, tácita antes e invisible. El que os da una idea os aumenta la vida y dilata la realidad en torno vuestro. Literalmente exacta es la opinión platónica de que no miramos con los ojos, sino al través o por medio de los ojos; miramos con los conceptos. Idea en Platón quería decir punto de vista» ${ }^{42}$. Mas hay, sin duda, un matiz que diferencia los dos términos y cuya raíz hemos ya comentado: la idea oscila entre la omnímoda presencia del concepto y la elaboración intelectual de la teoría. ¿Significará, entonces, que toda idea es concepto pero no todo concepto es idea? Para aclararnos definitivamente, tenemos que acudir a la función que "el pensamiento" va asumiendo en la mente de Ortega y que remite a su idea de cultura como necesidad.

La alusión recíproca entre conceptos que alumbra una estructura de original sistematicidad o ordenación histórico-vital es para Ortega alétheia; pero la luz de la revelación que las nuevas conexiones en perspectiva crean, pierde su lustro aparente de novedad en el uso -sea auténtico de la cultura o hemipléjico del erudito-. Luego el concepto, al alejarse el momento de su génesis instrumental, se recubre de explícita servicialidad, de una "costra utilitaria" que es su clara función intelectual, como acontece sobremanera cuando ingresa en una teoría científica. A tal concepto se le ha llamado eminentemente "idea" que se remonta a $1910^{44}$, podríamos decir que "contamos con" las cosas mediante los conceptos, pero tenemos ideas cuando nos "percatamos" de que las cosas son problemas, que es lo que nos lleva al "saber" como necesidad y a la auténtica cultura. Hemos aquí, entonces, algunas conclusiones decisivas. El pensamiento, y con él las ideas, en primer lugar, no conduce directamente al conocimiento, al saber científico, sino a toda certidumbre en tanto que mero saber a qué atenerse que responde a problemas $^{45}$. En segundo lugar, como los conceptos, según hemos visto, no son solo palabras, habrá que admitir ${ }^{46}$ que no pensamos solo con ellas, sino con imágenes, gestos, sentimientos o "silencios que hablan", porque la situación problemática de repente se resuelve o, como también puede ocurrir, no tenemos palabras para explicarla. Finalmente, la conexión entre conceptos e ideas que proporciona esta novedosa función vital del pensamiento, introduce de ahí a poco a lo que Ortega llamará las "creencias". Tal será el nombre para definir la cristalización de las ideas,

42 Ibid. p.789. Esta concepción se mantendrá inalterada en el pensamiento de Ortega. Cf. La deshumanización del arte, III, pp.867, 868 .

43 Cf. Meditaciones del Quijote, I, p.769.

44 Cf. Adán en el Paraíso, II, p.64.

45 Cuando Ortega afirma que la «Claridad no es vida, pero es la plenitud de la vida» (Meditaciones del Quiote, I, p.788) y aboga conquistarla con el concepto, no se refiere, naturalmente, a que hay zona de la vida sin conceptos, meras impresiones, sino a que la vida es menesterosidad porque es problema, y, por ello, necesidad de pensar. «Al fin y al cabo, la vida se nos presenta como un problema acaso soluble o, cuando menos, no a limine insoluble».Y el espíritu religioso eleva la problematicidad de la vida, en tanto que la introduce «a misterios todavía más intensos y peraltados». Ibid. p.789.

46 Cf. la función del sentimiento en Ortega, Ensayo de estética a manera de prólogo, p.676, o Marías, Introducción a la filosofia, p.238ss. 
pero también, y mucho más profundamente, la decantación histórica de un conjunto de conceptos que instalan al hombre en las profundidades de la verdad, porque nos permite "contar con" las cosas sin pensarlas, manifestando, por ello, el sentido de razón histórica o autenticidad de los proyectos personales y sociales. Marías desde 1947 llama brillantemente a las ideas como «las verdades a las que se llega» para saber a qué atenernos, mientras que a las creencias «verdades en las que estamos» y que no requieren pensamiento ninguno para ejercer su vigor interpretativo ${ }^{47}$.

Sirva como colofón, después de todo lo dicho, la siguiente aseveración de las Meditaciones: «Muy lejos nos sentimos hoy del dogma hegeliano, que hace del pensamiento substancia última de toda realidad. Es demasiado ancho el mundo y demasiado rico para que asuma el pensamiento la responsabilidad de cuanto en él ocurre. Pero al destronar la razón, cuidemos de ponerla en su lugar. No todo es pensamiento, pero sin él no poseemos nada con plenitud $\rangle^{48}$.

Téngase bien en cuenta que el joven Marías de veintiséis años que escribía su Historia de la filosofía (1941), o más aún el de los treinta y tres años que publicaba su compleja Introducción a la filosofía (1947), vivía, con sus propios argumentos, desde las certezas filosóficas que hemos aquí desgranado. En la primera obra que acabamos de mencionar, una vez llegado a exponer el pensamiento de Ortega, no duda con él a enjuiciar sin apelación posible a la epokhé husserliana, considerándola una precaución inútil. Desde el carácter intrínsecamente interpretativo de la vida, como había ido anunciando su maestro a partir de $1913^{49}$, el yo que reflexiona es irremediablemente ejecutivo, con lo cual debería suponer a otro yo, a su vez, que lo observase para cumplir con el propósito de describir sus propias vivencias en actitud puramente espectacular, lo cual daría lugar a un proceso infinito. Ya vimos que una descripción de una vivencia - la del sonido del río y del grito de la oropéndola- es una razón superpuesta y solo derivable del espontáneo interpretar de la vida. Un dolor o un rojo no es mera conciencia del dolor o del rojo, sino yo doliéndome o el rojo siendo visto, es decir, yo en tanto que «todo verificándose o ejecutándose» (proyectándose), como afirma Ortega en su Ensayo a manera de prólogo (1914); así que la interpretación ejecutiva (la perspectiva) es supuesto y razón de la misma "conciencia" "50. En la segunda obra de Marías que acabo de mencionar -auténtico manual de la razón vital-se reitera que la descripción como método, a pesar de haber cumplido con una importante función histórico filosófica, es de por sí insuficiente: es menester interpretar y buscar una certidumbre radical que organice sistemáticamente todas las ideas para dar al hombre claridad hasta su horizonte de ultimidades (los libros más técnicos de Marías concluyen siempre con un análisis de la muerte). A raíz de la mereología de Ortega, además, Marías defiende -y en cierto modo desarrolla- una lógica que prescinde de la fundamentación descriptiva -Fundierungy se organiza por "vivificación" 51 , lo que querrá decir en su obra madura, y volviendo una vez más a Ortega, "por amor". Finalmente, estrictamente relacionado con este

\footnotetext{
$47 \quad$ Ibid. p.79, 95.

48 Meditaciones del Quijote, I, p.785.

49 Cf. J. Marías: Historia de la filosofía, Obras, I, Revista de Occidente, Madrid, 1982, p.435. Cf. también, "Conciencia y realidad ejecutiva: la primera superación orteguiana de la fenomenología", en Acerca de Ortega, El Alción, Madrid, 1956; y, del mismo autor, "El ser ejecutivo y la fenomenología", en Ortega. Circunstancia y vocación, p.520. Cf. también el Prólogo para Alemanes de Ortega, de 1934, IX, p. 156.

50 Cf. Ortega: Ensayo de estética a manera de prólogo, I, p.688.

51 J. Marías: Introducción a la Filosofia, pp. 132-134, 137,138.
} 
rechazo al método husserliano, pero por razones más profundas que indicaremos, Marías entiende en 1947 que la reducción eidética revela su debilidad teórica cuando se aplica a "mi yo". Este es proyectivo, "futurizo"; su entificación en "el yo" como polo de actos de conciencia es la forma moderna de cosificar la vida ${ }^{52}$.

\section{Proyecto como apertura sistemática. La razón vital es personal}

De la lectura de las Meditaciones aquí propuesta, se nos revela con claridad por qué Marías asumirá pronto que "estructura" no es mera forma, tampoco un conjunto de elementos cuya dinamicidad elude explicaciones epistémicas y metafísicas. La profundidad del mundo se la proporciona la perspectiva de mi vida que pone en conexión sus elementos según el antes y el después, según la cercanía y la lejanía, y otorga un lugar imprescindible a cada uno respecto de los otros mediante el concepto, desvelando su función o sentido. Las conexiones de la realidad son aprehendidas conceptualmente al vivir, de ahí que todo lo que hay, al radicar en mi vida, es mundo: cuento con él como totalidad abierta y partes, me percato de sus niveles de realidad, pienso restructurando sus elementos en nuevas jerarquías de valor. La reducción del concepto a la semiótica verbal es una desfiguración filosófica, siendo todo precepto concepto y siendo la estética, en definitiva, ya teoría, si bien "intrínseca de la vida". Y la ética se refiere a la misma aprehensión de la realidad en "mi vida", de suerte que bueno y malo, como he mostrado en otro lugar, dependerá del sentido de su proyecto $^{53}$. Además, a la omnímoda conexión como función del concepto, sigue una liberación del pensamiento. Descubriéndose su función vital de "saber" en el sentido de saber a qué atenerse, el pensamiento obra con imágenes interiores o exteriores, con "silencios", con movimientos de cuerpos o de estados de ánimo, con palabras... con la entera circunstancia. Se aclara, entonces, la expresión con la que Marías desde 1947 y para el resto de su obra define la razón: «la vida misma en su función de aprehender la realidad en su conexión» ${ }^{54}$. Aquel "su" no se refiere a las conexiones del kósmos de la physis o de los actos de conciencia, sino a las de "mi vida", que para ser pensamiento o consciencia de sí en el mundo reabsorbe la circunstancia en el proyecto de quien voy a ser en ella, convirtiéndola en mundo histórico-social de una biografía personal. Con todo lo visto y con estas últimas anticipaciones teóricas, parecería que nuestro camino se ha allanado y divisamos su destino. El pensamiento filosófico debe levantar una estructura teórica verbal capaz de interpretar la vida individual, que es la verdadera realidad haciéndose. Ortega ha reiteradamente indicado que la fórmula que resume este afán se presenta ya expresada en las Meditaciones, y es harto conocida: "Yo soy yo y mi circunstancia, y si no la salvo a ella no me salvo yo», a la que sirve de precisa introducción otra que de pocas líneas la precede: «la reabsorción de la circunstancia es el destino concreto del hombre». El nombre que Ortega adoptó para tal fórmula fue "la estructura general de la vida"; Marías la ha llamado "estructura analítica" por proceder del análisis interpretativo de los elementos necesarios y por eso en conexión universal que estructuran la vida en

\footnotetext{
52 Cf. Ibid. p.198ss.

53 Cf. F. de Nigris: "Ortega et la Métaphysique”, op. cit. p.42 y, del mismo autor, "La razón vital de Ortega y la analítica existencial de Heidegger." Ideas y Valores, Vol. 61, n.148.

54 J. Marías: Introducción a la filosofía, p.144.
} 
tanto que vida humana, además permitiendo a quien vive conceptuarla con conciencia histórico filosófica de ser la realidad radical. Sin embargo, las cosas no son tan sencillas. Nos faltan todavía demasiados elementos para comprender la procedencia de la fórmula de Ortega, $y$, para lo que nos interesa, nos falta la fuente de ordenación o sistematicidad última de toda estructura que se presenta en la vida, incluso de aquellas estructuras teóricas verbales que pretenden dar razón de ella, como la analítica y la empírica. Tal "fuente", como he anticipado, es la vida misma en cuanto proyecto personal, porque quien vive se re-absorbe personalizando la circunstancia en "mundo", es decir, revelando proyectivamente que las estructuras empíricas del mundo son funcionales al encuentro personal, componiendo todas ellas una única estructura, como tal necesaria, que es "el hombre"55. Solo si llegamos a captar la génesis de esta idea en su estricta necesidad teórica, se aclarará la verdadera función filosófica de los términos "circunstancia" y "reabsorción", que he intencionadamente apartado hasta ahora; se alcanzará, además, la evidencia de que la vida es sistemática, concretamente sistema abierto; y, finalmente, que la apertura sistemática de la vida es su proyecto de amor personal que necesita al "hombre", en tanto que estructura empírica, como término medio de comprensión interindividual. Tenemos, pues, que volver a internarnos en las profundidades magmáticas de la obra orteguiana, dejarnos acompañar por su diluvio de ideas y saber distinguir, solidificadas, vetas que orienten su pensamiento, por lo menos tal y como orientaron a Marías para elaborar su antropología.

Lejos de estrenarse en 1914, la mereología de Ortega y su aneja epistemología pueden remontarse a cuatro años antes, a Adán en el paraíso, cuyo propósito es el de sostener que el arte vivo, en acto, es inseparables de su teoría, la estética. Es verdad que la concepción mereológica que allí se presenta es criticada por el mismo autor en una nota de 1915, pareciéndole irritantemente kantiana y leibneziana. Si bien ya Ortega habla de "punto de vista" o "panorama", todavía no hay conceptos ni ideas instrumentales que garanticen el rigor del escorzo en la perspectiva, ni hay claramente, como veremos, circunstancia y reabsorción; pero sobre todo allí todavía se creía -como también indica el autor en una nota de 1915-que el órgano crea su función, cuando, como hemos comprobado, el órgano es función. A pesar de estas flaquezas, la exposición es suficientemente sólida para que con ella Ortega arribe a un logro decisivo para el porvenir de toda su doctrina. Se trata, «siguiendo una tendencia que se impulsa desde el Renacimiento, de la disolución de la categoría de sustancia en favor de la de relación $\rangle^{57}$. La argumentación es intelectualmente cautivadora, pero más aún su conclusión cuando es aplicada a la pretensión general del idealismo y del realismo. Vamos a verlo brevemente.

El punto de partida ya lo conocemos: «el individuo, sea cosa o persona, es el resultado del resto total del mundo: es la totalidad de las relaciones $\rangle^{58}$. Por lo tanto, cuando el pensador se pregunta: ¿qué es una cosa?, responder significa catapultarse inevitablemente al conocimiento de la totalidad; mas resulta que esta no la posee; Dios, quizá, nos diría Ortega en las Meditaciones, es perspectiva de amor ideal, de comprensión última de todas las cosas, pero el hombre no es del todo semejante a

\footnotetext{
J. Marías: Antropología metafisica, p.75.

Cf. J. Marías: Ortega. circunstancia y vocación, p. 464-468, 508ss.

Adán en el paraíso, II, pp.66, 67.

Ibid. p. 68 .
} 
Él, ni tampoco es, como vio Platón, una bestia que no necesita pensar porque no se percata del problema que es el mundo y del misterio que es la vida ${ }^{59}$. El realista, por lo tanto, al pretender reproducir una cosa concreta, tendrá de ella solo un ideal, pues es infinita la tarea de definirla con todas las demás cosas que existen. Realismo es, en el fondo, idealismo. El idealista, por otra parte, para saber lo que la cosa es, busca un ideal de ella, si bien para forjarlo adecuadamente tendría que contemplar todas y cada una de las cosas concretas. El idealismo es realismo. ¿Quiérase con ello concluir que la filosofía y todas las ciencias en la medida en que no pueden captar la realidad concreta, desnuda de todas sus interpretaciones, son mera ficción, es decir, irremediable desfiguración de lo real?

Las ciencias buscan formular leyes, y ellas son "ficción" de lo concreto porque su método es explícitamente "abstracción y generalización" 60 . Tal parecería ser también el destino de la teoría estética respecto del gesto artístico; sin embargo, acaba de mostrar Ortega "disolviendo" la categoría de sustancia en favor de la de relación, que nada concreto puede ser captado en la vida sin que con tal captación se organice, a la vez, un punto de vista o pan-orama acerca del todo que lo circunda. Lo concreto es organización individual de totalidad, así que el menor gesto artístico o intuición científica son sendas declaraciones estéticas y epistémicas; son, en definitiva, puntos de vista que dan "valor" a las cosas en tanto que inevitablemente "realizan" en ellas un "ideal” de totalidad ("el escorzo" de las Meditaciones) ${ }^{61}$. ¿Pero cuáles serán, finalmente, esos ideales? Si un órgano crea su función, la función es creada a su vez por una necesidad que, finalmente, concluye Ortega en esta obra -y para siempre en su doctrina-, es la manifestación de un problema ${ }^{62}$. Las ciencias y el arte son quehaceres que responden a distintos problemas de la vida, $\mathrm{y}$, en función de ellos, cada una descubre su ideal -o ficción- y forja técnicas apropiadas. El ideal de las ciencias es el de reducir al mínimo el carácter interpretativo de la vida ${ }^{63}$, ofreciendo fórmulas generales -leyes- que interpretan lo que es "materia" en ella.

El arte, sin embargo, trasciende el punto de vista material porque acepta que la vida es, siempre, realización de una totalidad, es decir, interpretación, con lo cual el ideal del arte, como dice espléndidamente Ortega, es "ficción de totalidad". "Ficción" significa aceptación de que la verdad de las cosas no se da en el intento del pensamiento que busca adecuarse a ellas, disolviéndose, así, el dinamismo de sus relaciones, sino en el arte de perfilarlas, proyectarlas, en definitiva de realizarlas en la totalidad. A la pretensión adecuacionista compartida por realistas e idealistas, el arte se impone la mayor fidelidad a la realidad, el mayor positivismo fenomenológico, porque acepta que la perspectiva de lo real es infinitud, virtualidad, interpretación. «¿Cómo poner de manifiesto la totalidad de relaciones que constituye la vida más simple, la de este árbol, la de esta piedra, la de este hombre? De un modo real es esto imposible; precisamente por esto es el arte ante todo artificio: tiene que crear un

$59 \quad$ Ibid. p.64.

$60 \quad$ Ibid. p.67.

61 «No existe, por lo tanto, esa supuesta realidad inmutable y única con quien poder comparar los contenidos de las obras artísticas: hay tantas realidades como puntos de vista. El punto de vista crea el panorama. Hay una realidad de todos los días formada por un sistema de relaciones laxas, aproximativas, vagas, que basta para los usos del vivir cotidiano. Hay una realidad científica forjada en un sistema de relaciones exactas, impuesto por la necesidad de exactitud. Ver y tocar las cosas no son, al cabo, sino maneras de pensarlas». Ibid. p.60.

62 Cf. Ibid. p.63; y siendo "misterio", no lo olvidemos, el problema religioso. Cf. supra nota 44.

63 Propósito cuyo límite expresado por la ciencia misma, podríamos decir, es el principio de incertidumbre de Heisenberg, si bien muchos filósofos cientificistas, sorprendentemente, no lo respeten. 
mundo virtual. La infinidad de relaciones es inasequible; el arte busca y produce una totalidad ficticia, una como infinitud» ${ }^{64}$. Con tal punto de vista, que busca hacerse cargo abierta e íntegramente de la realidad ${ }^{65}$, el arte gana la perspectiva dramática de quien vive, de su capacidad y necesidad de realizar la vida creando su mundo -lo que Ortega llamará "estilo"-, y que deja, finalmente, como precipitado de tal realización biográfica y personal, una idea de la vida en cuanto tal, "su forma", que es inevitablemente artística. «Lo que debe proponerse todo artista es la ficción de la totalidad; ya que no podemos tener todas y cada una de las cosas, logremos siquiera la forma de la totalidad. La materialidad de la vida de cada cosa es inabordable; poseamos, al menos, la forma de la vida $»^{66}$. Con estas premisas Ortega sigue en Adán en el Paraíso reconociendo que "vida" significa pletóricamente "vida biográfica", individual, y que su problema es "el hombre", refiriéndose -en uno de los dos sentidos que suele tener esta palabra en su obra ${ }^{67}$-a la realidad plena de mi yo que se hace ejecutivamente, aquí y ahora.

Ahora bien, en esta obra de 1910 la mereología no está suportada por el riguroso análisis epistemológico de las Meditaciones, pero se prepara su ruta mediante algunas señas de identidad, esencialmente tres, de lo que se va llamando "razón vital". Inspirándonos en ellas, acompañándolas por sus inmediatos desarrollos teóricos, vamos a comprobar que el sentido de la razón vital es el proyecto personal y que "la circunstancia" de la que habla Ortega a lo largo de su obra es una estructura a él funcional. Con ello habremos encontrado el camino para aclarar, como concluiremos en el último apartado, que la unidad de la circunstancia empíricamente funcional para la realización del proyecto personal es lo que Marías llama "el hombre".

En primer lugar, ante nuestro análisis mereológico y epistemológico de Las Meditaciones y sus antecedentes en Adán en el Paraíso, se impone lo siguiente: que en la mente de Ortega se fortalece la idea de que ningún ideal adecuacionista de la verdad puede protagonizar la tarea que es el pensamiento, ni que una epistemología descriptiva y representacionalista es el instrumento de tal adecuación, ni, finalmente, que una lógica sustancialista le sirve de norma. No hay una "nuda realidad" de las cosas. Este error ha paradójicamente conducido al filósofo, para adecuarse a ellas, a "un ideal" de cada una en la totalidad -el ser y el ente ${ }^{68}$.. Y al no haberse reconocido como un mero "ideal" interpretativo - como una "ficción"-, el realismo del ente ha tenido que confesarse finalmente a sí mismo idealismo de la conciencia; y este, siguiendo el mismo afán adecuacionista, dar luz a sus versiones transcendentales donde las facultades configuran objetos o las intuiciones categoriales los elevan a esencias. Realidad, sin embargo, no es primariamente sustancia u objeto de actos, sino relación, es decir, profundidad y relieve, ordenación, con lo cual su aprehensión efectiva no es adecuación sino "ficción", interpretación, perspectiva: aprehensión conceptual en que cada elemento cobra valor de verdad -su "idea" o "aspecto"-

$64 \quad$ Ibid. p.68.

65 Desde el arte Ortega encuentra su positivismo absoluto, que no tiene, por lo tanto, método fenomenológico descriptivo. La mirada de Ortega es la de "mi vida", que "interpreta viendo y ve interpretando".

${ }^{66}$ Ibid. p.68. La diferencia entre filosofía, ciencia, arte y religión es un tema recurrente a lo largo de la obra de Ortega. Cf. la nota 91, p. 163 de J. Marías a las Meditaciones del Quijote de Ortega, ed. Cátedra, Madrid, 1984.

${ }_{67}$ El otro, como vamos a ver, es "el hombre" en general, es decir, la estructura impersonal que componen las ideas creencias, opiniones, usos... que Ortega, finalmente, en El hombre y la gente, llamará nostridad.

68 Cf., para una consideración del ente como a priori transcendental de la metafísica antigua, La Idea de Principio en Leibniz de Ortega. 
según la función o sentido que realiza dinámicamente respecto de todos los demás. Y como la función no está dada en el órgano, sino descubierta funcionando, esto es, inventada e intensificada instrumentalmente en la perspectiva, resulta que esta es potencia de realidad, que es lo mismo que decir, de verdad ${ }^{69}$. Sustancia, por lo tanto, es relación porque no es actualidad sino virtualidad en perspectiva. Y las "circunstancias" de las que nos habla Ortega en las Meditaciones -podemos ahora empezar a explicar- son partes o estructuras en relieve de un horizonte último y abierto -porque dinámico- que es "la circunstancia": sistema abierto por la perspectiva que reordena o -introduciendo finalmente otro término fundamental"reabsorbe" sus elementos.

En segundo lugar, cuando afirmamos que la perspectiva reordena o reabsorbe, significa que se reinterpreta unitariamente y sin solución de continuidad porque responde a un mismo problema. Tal problema es el que define necesariamente la vida desde su raíz como razón. Y como no posee una respuesta definitiva a su problema -si así fuera duraría un instante y no habría perspectiva- la aprehensión de la razón vital es "programa", "pretensión", o como finalmente dirá Ortega "proyecto". Este término no denota una imperfección de la vida; más bien ella -si se me permite la aparente tautología- está "viva" porque se recrea, sin agotarse, en el problema que la define, que es, por eso, verdadero principio (arkhé) cuyo fin (télos) no tiene término (péras) ${ }^{70}$. Y por eso también, como advertimos desde el comienzo de este estudio, la vida no es sistema -lo que sería remitir su realidad a un sinfín de órdenes estructurales superiores- sino apertura sistemática, que es lo que la hace "realidad radical": ámbito donde radica y existe cualquier otra realidad.

En tercer lugar, Ortega afirma desde Adán en el Paraíso que "el problema" al que la vida responde es "el hombre", refiriéndose a la vida individual biográfica, es decir, a mi persona tal y como me encuentro aquí y ahora en mi vida, que corresponde al primer "yo" de su fórmula: "yo soy yo y mi circunstancia y si no la salvo a ella no me salvo yo». Esto quiere decir que "el problema" de la vida para Ortega no es descubrir lo que son las cosas para adecuar el pensamiento a ellas, sino responder a la cuestión personal: ¿quién soy? La vida como totalidad es una ficción, es decir, una interpretación que, entendemos ahora, soy "yo": reabsorción de quien he sido en vista de quien voy a ser, esto es, perspectiva o proyecto personal -el sentido del segundo "yo" de su fórmula-. Es el pro-yecto, pre-tensión o pro-grama personal lo que abre la perspectiva y el tiempo en sentido esencialmente biográfico; y es en función de tal apertura sistemática que cobran conexión, orden o sentido todos los elementos circunstanciales: se re-absorben biográficamente $\mathrm{y}$, entonces, existen o re-sisten en el tiempo de mi vida, "por" y "para" mi proyecto, desde mi pasado que se recrea en vista de mi incierto futuro, realizando una idea o ficción de mí. En definitiva: «La reabsorción de la circunstancia es el destino concreto del hombre».

El concepto de alétheia como desvelamiento del sentido de las cosas que hemos encontrado en las Meditaciones, nos ha remitido a la fuente última que da razón de la conexión sistemática de cada cosa en vista de las demás, es decir, al proyecto personal ${ }^{71}$. Todas las circunstancias existen o re-sisten en la re-absorción del proyecto

69 Es la fuente proyectiva, personal, de esa potencia que marca un límite para toda analogía con el "poder de la realidad" de Zubiri.

70 Cf. para esta cuestión, F. de Nigris: "Ortega et la Métaphysique”, op. cit. p.28ss.

71 El reconocimiento de la conexión de las dos ideas de verdad está plenamente asimilada en el pensamiento de Marías, pero hay que reconocer y siempre aconsejar la lectura del minucioso libro de R. Huéscar ya mencionado 
en que me encuentro; todas, por lo tanto, se realizan -o se hacen reales-unitariamente en el tiempo que la perspectiva personal ha abierto. La circunstancia es virtualidad que se va desvelando en perspectiva, en el tiempo biográfico, porque la fuerzo en mi proyecto a llegar a ser en el presente el escenario de quien pretendo ser en el futuro, como reabsorción de quien he sido en el pasado; en otras palabras, la continua revelación de la circunstancia, su alétheia, es, a la vez, una revelación de mín $^{72}$. Sin embargo, si lo que mueve la vida, la fuente de ordenación o de reabsorción de la circunstancia es una pregunta personal que compromete a quien vive a comprenderse circunstancialmente, para que el proyecto responda a la pregunta que lo anima y transciende deberá aparecer otra vida, otro proyecto de personalización, en vista del cual me comprendo, me encuentro. Ello nos introduce definitivamente a la necesidad de "el hombre" en tanto que estructura empírica de la vida humana. Vamos a verlo brevemente y a concluir.

\section{El hombre como nostridad y como "estructura empírica"73}

Ortega nos ha introducido a la idea según la cual los conceptos no tienen otra materia respecto de las cosas; no son, aquellos, cosas espirituales que han solidificado las cosas materiales dándoles voz a través de otras, sonoras, las palabras. Cuerpo y psique, con todas sus facultades como -en el caso de esta última- la memoria y la imaginación, son para Ortega circunstancias, al igual que cualquier otra "materia" que me encuentro en mi pasado para rencontrarme en mi futuro: circunstancia es todo lo que no es mi proyecto aquí y ahora y que por y para él se reestructura sistemáticamente $^{74}$. "La pura materia" no existe, siempre me encuentro con ella personalizándola, es "ficción" o interpretación personal de totalidad. La cuestión que ahora se pone, sin embargo, es la siguiente: ¿qué idea más precisa deberíamos tener de la circunstancia a raíz de su función, en tanto que horizonte abierto que reabsorbe sistemáticamente todas las estructuras o circunstancias de la vida, así

por nosotros, que, en el fondo, no tiene otra pretensión que captar esa novedad teórica de Ortega.

72 Hemos aquí, por lo tanto, el nexo más profundo entre la alétheia de las cosas como desvelamiento de sus conexiones ordenadas - o sentido- y la alétheia como fuente de ordenación de ese desvelamiento (el sentido del proyecto). Descubrir un vaso, un cuchillo, Dios, es descubrirme, por ejemplo, a mí como quien bebe quien corta, quien puede ser radicalmente amado o perdonado. Aquí estriba la radical diferencia entre la proyectividad y la intencionalidad. La autoconstitución egóica en ningún momento se aclara en la correlación noético-noemática; habría que remontarnos a la dimensión del pensamiento husserliano que se refiere a la conciencia interna del tiempo, si bien nunca el fundador de la fenomenología ha puesto la retensión y la protensión al servicio de la autoconstitución del ego; y el flujo de la conciencia, hasta sus últimos manuscritos, ha oscilado entre la admisión de su carácter egóico o anónimo. Cf. F. de Nigris: Intencionalidad, pasividad y conciencia interna del tiempo en el pensamiento de Edmund Husserl, op. cit.

73 Cf. Sirva de acompañamiento para este apartado sobre la"estuctura empírica de la vida humana", F. De Nigris: Libertad y Método. El liberalismo desde la perspectiva personal de Ortega y Marías. Editorial FUE. Madrid, 2005, capítulos IX y X.

74 Desde 1911: «Mas ¿qué son las circunstancias? ¿Son sólo estas cien personas, estos cincuenta minutos, esta menuda cuestión? Toda circunstancia está encajada en otra más amplia; ¿por qué pensar que me rodean sólo diez metros de espacio? ¿Y lo que circundan estos diez metros? ¡Grave olvido, mísera torpeza, no hacerse cargo sino de unas pocas circunstancias, cuando en verdad nos rodea todo. Vejamen del orador, II, p.141. Y en 1914, con más precisión, aclarando que tanto el mundo exterior como el interior forman la circunstancia: « $i E l$ mundo exterior! Pero ¿es que los mundos insensibles -las tierras profundas-no son también exteriores al sujeto? Sin duda alguna: son exteriores y aun en grado eminente». Meditaciones del Quijote, I, p.780. Cf. J. Marías: Ortega. Circunstancia y Vocación, p.496, 497. 
como - recuerda Ortega en las Meditaciones- la idea de "naturaleza" ha pretendido resumir las estructuras materiales o "Dios" ser suma de todas las perspectivas? Sin duda, remitiéndonos al sentido personal del proyecto, resulta que la revelación íntegra de las estructuras circunstanciales, en la reabsorción de la perspectiva de sus conexiones en mi vida, apunta a revelar una idea de mí, con lo cual deberíamos llamarla "mi mundo". La circunstancia es mía, se está personalizando en mundo, es "su destino", y salvándola a ella, es decir, revelando sus conexiones, revelo una idea de mí. ¿Pero no significa con eso volver a caer en una nueva forma de solipsismo?

Sería este el caso si la vida pretendiera, como el pensamiento en la conciencia idealista, adecuarse a las cosas, supeditándose su realidad a una idea mía de su existencia -que no habría entonces más remedio que poner entre paréntesis para seguir filosofando (epokhé)-. Sin embargo, al tener la vida otro proyecto, porque responde a la cuestión personal ¿quién soy?, y existiendo las cosas en el tiempo biográfico abierto por y para encontrarme, resulta que ya me he encontrado con el prójimo -empezando por mis padres-, de lo contrario no tendría ninguna idea de mí -que evidentemente tengo-. Un hombre solo, que nunca hubiese visto a nadie, no tendría ningún concepto de sí mismo; carecería, en realidad, de todo concepto porque conceptuar es lo mismo que responder personalmente al problema de mi vida: comprenderme siendo comprendido y, a la vez, comprendiendo al otro.

Aprehensión de la realidad es, entonces, comprensión personal, personalización de la circunstancia en mundo, necesaria presencia del prójimo en mi vida. Pero la vida no es pura ni primariamente interindividual, es decir, el trato con el otro no ofrece de inmediato proximidad, sino más bien lejanía: la infinita que recorre entre dos intimidades que no saben que esperarse la una de la otra. El otro no es de inmediato próximo; su vida no me revela súbitamente una dimensión, acaso irrenunciable, de mi personalidad; su mundo no es, instantáneamente, un conjunto de posibilidades imprescindibles para ser yo mismo. El otro, al pronto, busca ser mero reciprocante de mis actos en tanto que procura anticiparlos y anticiparse a mí para responder a su vida.

Vivir no es un mero estar en el mundo, sino encontrarme en él por y para el prójimo, con lo cual "mi mundo" es una creación de proyectos y afianzamiento de trayectorias que parten del mundo en general, que no es de nadie y cuyas posibilidades son la decantación histórica de otras vidas anónimas para mí. "Mi mundo", entonces, se va labrando su figura en vista del mundo en general, personalizando "el hombre" -de mi época, de mi generación- que tácitamente protagoniza la sociedad y al que mi familia inevitablemente -si bien particularmente- me ha introducido, asimilando yo sus ideas, creencias, opiniones, usos, y creyéndome a menudo que todos ellos son míos, confundiéndome con "él". En cualquier primer trato humano, por lo tanto, como Ortega acabará explicando detenidamente en El Hombre y la Gente ${ }^{75}$, las posibilidades íntimas son las últimas en crearse, porque entre yo y tú siempre está "él": un nosotros o nostridad que permite a mí, originariamente, ser "reciprocante" del otro; y conforme ese trato se hace más próximo, sus términos exclusivos, la nostridad se acota a la vez que se profundiza, haciéndose el otro llamada irrenunciable de personalización: tú, amigo, padre, madre, hijo, esposo... Con esta estructura interpretativa, trina, analógica -más bien metafórica-, consecuencia del carácter proyectivo personal de la razón vital, Ortega critica la concepción descriptiva de

75 J. Ortega y Gasset: El hombre y la Gente, X, p.199ss. 
la alteridad expuesta por Husserl sobre todo en las Meditaciones cartesianas. Es este un ejemplo claro de cómo la diferencia de método y de categorías filosóficas -empezando por el contraste proyectividad-intencionalidad-lleva forzosamente a parajes teóricos lejanos ${ }^{76}$.

Marías, justo un año después de la redacción del genial libro de Ortega -editado póstumo-, pudo conversar largamente con su maestro en el Instituto de humanidades (1948), cuyos cursos versaron sobre la vida colectiva. La obra que encumbra ese periodo de reflexiones sería La estructura social (1955), pero tres años antes, desde 1952, en La Psiquiatría vista desde la Filosofía (1952), y ya en forma madura, en La vida humana y la estructura empírica (1953)- Marías extiende el concepto de "hombre" a todas las estructuras circunstanciales de la vida, siendo la estructura social solo una de ellas.

La razón de ello ya la hemos visto: la pura materia no existe, con lo cual el cuerpo también tiene que ser una estructura por y para la vida, es decir, revelar su sentido en el proyecto; y el rostro, dirá Marías, en el ámbito de una larga reflexión -que tiene interesantes analogías con Levinas-, es "el órgano somático de la futurición", así como el ojo el "primer inteligible" "77. A la revelación proyectiva de las estructuras circunstanciales, Marías la define "instalaciones". Se trata de la dimensión del "estar", una vez que, habiendo vida -el mero "haber"-, pretende ella ser intensamente vida humana -la dimensión del ser o, más bien, del "siendo"-. En este sentido, la vida, en tanto que pretensión personal de comprensión circunstancial, podría llegar a imaginarse con otras estructuras empíricas que no tienen por qué ser aquellas que, en efecto, encontramos en este mundo. Cada uno de nosotros es hombre con un cuerpo que posee, normalmente, dos brazos y dos piernas; pero cabría imaginar una vida con el mismo proyecto humano y cuya corporeidad fuera gas o agua, cuya forma de comunicarse fuese telepática, y ser "la tierra", aquella que pisamos, otro planeta; pero en todo caso debería haber una similitud corporal entre individuos para que nos encontrásemos y comprendiésemos biográficamente como yo y tú. El cuerpo es por y para el proyecto, de ahí su funcionalidad empírica. Esta lógica de

76 También Heidegger en Sein und Zeit (Max Niemeyer Verlag, Tübingen, 1967), entiende que el hecho primario del existir (Dasein) es estar en el mundo (in die Welt sein); que la estructura primaria de la significatividad (Bedeutsamkeith), en tanto que totalidad originaria de los "respectos" sistemáticamente trabados del todo que es el mundo, es el Uno (Das Man), el "se" impersonal (p.133). El Uno está ya abierto en el mundo por cada existir humano, que se interpreta en él comprendiéndose a partir de lo comprendido, es decir, mediante un discurso, un empleo lingüístico, una disposición anímica general que funcionan como término medio (Durchschnittlichkeit) del ser de un existir con otros (Mitsein) (p.124ss). El existir es, por lo tanto, coexistir (Mitdasein) entre hombres que no están meramente presentes como las cosas, y en la medida en que anticipan sus posibilidades de ser en el mundo se preocupan entre sí de sus existencias. El cuidado o preocupación de mi existir (Sorge), en efecto, como si de una tautología se tratase, es cuidado y solicitud para con el prójimo (Besorgen, Fürsorgen, pp. 124, 193), posibilidad de trasparencia de una existencia para con otras. Sin embargo, el concepto de sentido (Sinn) para Heidegger no se resuelve en la apertura personal del proyecto del existir (Entwurf). El tiempo no está abierto (Ekstasen) por una razón biográfica; tampoco el presente y sus horizontes pasado y futuro se autentifican a partir de la comprensión interindividual. El círculo hermenéutico de la Sorge no es capacidad de apertura del proyecto (Entwurf) en vista de la interpretación de "el hombre" para la ampliación de sus posibilidades históricas de comprensión interindividual en la nostridad. Por todo ello, a diferencia de lo que ocurre con el pensamiento orteguiano, el tiempo llega a ocupar el concepto de "sentido": es el horizonte -Woraufhin- de manifestación del ser en el proyecto del existir. Al contrario, y sin que podamos entrar en ello, el concepto de togetherness de Marcel, acompañado por los predicados de disponibilité, engagement, communion, présence, se aproxima más a lo que entiende Ortega por nostridad como función de personalización (Cf. G. Marcel, Homo Viator, Aubier, Éditions Montaigne, Paris, 1944, pp15-35).

77 J. Marías: Antropología metafísica, p.133. 
"instalación" tiene que ser aplicada a todas las estructuras o circunstancias de la vida. La instalación corporal, sea cual sea, genera, es decir, da a luz generaciones sucesivas de personas que heredan "el mundo" y reobran sobre la idea del hombre que le pertenece, lo que permite que haya historia. Podría concebirse, por lo tanto, que el individuo no muriese, que no fuese heredero de humanidad, y, sin embargo, la instalación corporal es mortal y fuerza a la interpretación histórica; fuerza, la muerte corporal, a un proyecto mundano determinado entre otros posibles, dando a la vida, de esta suerte, un significado proyectivo concreto que se escalona entre edades como inevitable argumento biográfico del envejecimiento biológico. La estructura biológica, la división celular, la consistencia última de la corporeidad y su duración, entonces, cualesquiera que ellas sean, se degradan y se interpretan en vista de la muerte, así que que el proyecto, atravesando generaciones y épocas sucesivas, significa "variación antropológica": compromiso creador de cada persona con "el hombre" que está continuamente implicado y complicado en sus vidas. Y, siguiendo a esa lógica, cabría también pensar en una reproducción sin varón y mujer, como la de nuestras células o de algunos animales. Sin embargo, "el hombre" es instalación sexuada: interpretación de quien vive en vista de un cuerpo ab initio polarmente orientado hacia otro, de suerte que la interpenetración de vidas significa interpenetración de mundos diferentes: "campos magnéticos" de fertilidad humana. Todas las estructuras que descubre Marías en su Antropología Metafísica, en definitiva, plantean un nivel intermedio entre la estructura analítica que descubre Ortega y la facticidad concreta. Tienen, por ello, "cierta permanencia" estructural propia que emerge del nivel fáctico, pero la unidad que configuran es necesaria. "El hombre", en efecto, es necesario como término medio de la analogía personal: es el sistema unitario de las instalaciones en que empíricamente se encuentra la vida humana y que, en su conjunto, es "abierto" sistemáticamente por y para el proyecto, cuya verdad es intensidad y autenticidad de comprensión -o amor- en el encuentro personal.

«La estructura empírica, pues, no es un requisito -o un conjunto de requisitos- de la vida humana, a priori respecto de cada una de las vidas posibles. Pero pertenece de hecho a las vidas humanas en las cuales empíricamente la descubro. No solo de hecho, sino además de una manera estable -lo cual no significa sin embargo que sea permanente-; y por ser así, también a la estructura empírica le pertenece un cierto apriorismo; pero no respecto a cada una de las vidas posibles, sino respecto a las muchas reales que encuentro en mi experiencia.

La vida humana es así, aunque en principio pudiera no serlo. Y ese «así» no tiene un mero carácter fáctico, sino estructural y configurador. Lo cual significa que la vida, además de tener la estructura analítica y universal constituida por sus requisitos necesarios, sine quibus non, ha de estar empíricamente estructurada, con una u otra estructura empírica. Pero esto quiere decir que la estructura empírica, tomada globalmente, es un ingrediente o requisito de la estructura analítica de la vida humana.

Vista desde esta perspectiva, la estructura empírica aparece como el campo de posible variación humana en la historia» ${ }^{78}$.

$78 \quad$ Ibid. p.75. 
En el primer apartado, hemos reconstruido una teoría mereológica según la razón vital, siguiendo las pistas que Marías ofrece en su Antropología Metafisica y que, según el mismo filósofo indica, se derivan de las primeras obras de Ortega, concretamente de las Meditaciones del Quijote. Una vez fijados desde esta semántica filosófica los conceptos de sistema, estructura, órgano, función y sentido, hemos penetrado en dicha obra de Ortega para comprobar que su mereología es inseparable de su teoría del conocimiento, y que, con ambas, se tiene un acceso novedoso a su metafísica de la vida.

\section{Recapitulación y conclusiones}

La vida individual como perspectiva se nos ha revelado como la fuente de apertura sistemática o de "reabsorción" de toda estructura, de suerte que tanto el "percepto" como el "concepto" se estructuran según la función que tienen en la vida: captan las cosas en su conexión, porque son sus mismos aspectos -ideas-, de suerte que el esquematismo conceptual es, en principio, tan ilimitado como las posibilidades perceptivas. Aquel, en efecto, no se plantea como en Kant desde el conocimiento, sino desde la vida que -según palabras de Ortega- no es un mero "ver pasivo", lo que haría de la percepción del mundo "un caos de puntos luminosos"; tampoco consiste en "pura visión intelectual", sino que mi vida, en cuanto perspectiva, es inevitablemente, sin ningún esfuerzo reflexivo añadido - "un ver activo, que interpreta viendo y ve interpretando; un ver que es mirar." La "pura materia" o la "pura idea", por tanto, son abstracciones teóricas; de hecho, son conceptos que devienen "ideas" en la medida en que funcionan, a su vez, como puntos de vista que abren escorzos teóricos para la comprensión de la vida misma (son "órganos de profundidad").

Desde estos supuestos, la conclusión que hemos alcanzado a lo largo del segundo apartado no podía ser más grave: lo que se ha llamado en ciencia o en filosofía "cosas" tiene tanto de "circunstancia" como lo que se ha llamado "psique" o "cerebro", "materia" o "espíritu". Son todas ellas estructuras o "circunstancias", y como tales existen o resisten en perspectiva, es decir, su espacialidad consiste en su continuo reordenarse en el tiempo biográfico de mi vida. En tal sentido se aclara la idea orteguiana según la cual "mi vida" es "la realidad radical", a saber: que todo lo que hay, para "ser real", tiene que radicar en mi vida, esto es, circunstancialmente o en perspectiva. Este es también el trasfondo teórico que lleva a Marías, por una parte, a definir en su obra temprana la razón vital como "la aprehensión de la realidad en su conexión" (Introducción a la filosofia, 1947) o "la organización real de la realidad" (Idea de la Metafísica, 1955); y, por otra parte, a teorizar "el hombre" como la unidad sistemática del conjunto de estructuras que, por su relativa permanencia, garantiza que la vida humana sea encuentro personal. Así, en Antropología metafisica (1970), la corporeidad, la mundanidad, la sociedad, la condición sexuada, son, en cuanto tales, sin atender a su contenido concreto, supuestos necesarios para la comprensión entre "yo" y "tú".

Ahora bien, si el hombre es el conjunto de estructuras que se reordenan en la apertura sistemática de la vida individual (de suerte que cada vida, a pesar de su originaria facticidad, se estructura antropomórficamente), queda por dilucidar cuál es el sentido último de la razón vital. En otras palabras, preguntarnos aún: ¿Cuál es el problema de la razón de la vida que la convierte en perspectiva o interpretación 
antropomórfica? ¿Por qué y para qué se abre la perspectiva temporal, espacializante, en que consiste la vida como interpretación pre-reflexiva, de suerte que la estructura empírica, independientemente de su contenido, le sea necesaria? El tema de estas preguntas es el problema metafísico de la vida como realidad radical. Si quisiéramos expresar esta cuestión en términos heideggerianos -a pesar de que el filósofo alemán nunca llegó a planteársela ${ }^{79}$, deberíamos preguntarnos por el sentido de la apertura (Erschlossenheit) del existir humano que confiere criterio último de verdad al discurso hermenéutico (Rede) y sus posibilidades de comprensión (versthehen); no obstante, ello equivaldría a cuestionarse el sentido de la Sorge como razón de la apertura extática temporal del existir humano (Dasein). La respuesta de nuestro trabajo a esta pregunta ha sido la siguiente: la razón vital es proyecto personal de comprensión circunstancial, de modo que toda estructura es órgano para la comprensión entre yo y tú, lo cual postula una unidad antropomórfica como término medio posibilitante de esta misma comprensión, entre otros términos medios empíricamente posibles (el hombre podría estar hecho de gases, percibir infrarrojos y estar instalado proyectivamente en otro universo posible, con otras estructuras sociales, etc.). El problema de la vida, pues, sería personal: ¿quién soy?, y "el hombre" sería la estructura necesaria para la comprensión de mí mismo con el otro.

Sin embargo, para alcanzar esta conclusión, que pertenece al nivel filosófico de Marías, nos hemos dirigido una vez más al pensamiento de Ortega, concretamente a Adán en el paraíso (1910), en busca del origen del concepto "proyecto", que es la primera formulación "personal" de la razón vital. A diferencia del Entwurf heideggeriano, este concepto, en Ortega, equivale a "mi yo", ejecutivamente entendido. Lejos de ser ajeno a su teoría mereológica y epistemológica, se nos ha revelado, a lo largo del tercer apartado, como la fuente de apertura sistemática en que consiste la perspectiva. Recapitulemos brevemente nuestro recorrido y las correspondientes conclusiones.

En el segundo apartado subrayamos con Ortega que la relatividad entre fondo y superficie en que consiste la realidad - sin la cual esta sería "plena transparencia", es decir, "nada"-, es justamente la perspectiva como continua "realización" de lo real, como "potencia de realidad". En efecto, "perspectiva" es continuo escorzo o individuación de las cosas trabadas en estructuras cuyo horizonte unitario indefinido varía con ellas. Es lo que permite decir a Ortega que cada cosa es "centro virtual del universo". La perspectiva, entonces, es espacialización y, por tanto, apertura temporal, continua potencia de realidad. ¿Pero cuál es "la razón" de la perspectiva, que es apertura temporal, presente continuo, recreación de pasado en el futuro y de futuro en el pasado, es decir, potencia de espacio? Esta cuestión nos ha llevado a lo largo del tercer apartado a recuperar los fundamentales conceptos orteguianos de "problema" y "necesidad", remontándonos a Adán en el Paraíso.

Cada ciencia -sostiene Ortega en esta obra- responde a distintos problemas de la vida, $y$, en función de ellos, descubre su "ideal" cognoscitivo, que es una determinación abstracta y general de lo que son las cosas concretamente, en su continua individuación. El ser físico, el ser biológico, el ser matemático..., son ficciones de totalidad, definen lo que cada cosa tiene que ser, científicamente, en la realidad, y, por tanto, adecuan el pensamiento a una idea general y exacta de

79 Que es lo que traza una distinción ineludible entre las hermenéuticas fenomenológicas y la razón vital. Cf, F. de Nigris, "Ortega et la métaphysique", op.cit. 
ellas. Sin embargo, el ideal del arte, al contrario, es lo individual, lo ejecutivo, lo irrepetible, es decir, su punto de vista pretende ser el mismo de la vida. Esto, como vimos a finales del tercer apartado, tiene diversas consecuencias. El arte libera el pensamiento porque se instala en la ficción misma, asume que las cosas son infinitas posibilidades de escorzo perceptivo y conceptual, de suerte que cada una puede ser punto de vista o centro virtual para la comprensión de las demás. Así, el arte revela que más allá del pensamiento como adecuación, la vida es perspectiva, comprensión inagotable de lo real. El valor del saber científico es la fidelidad a su ideal, a su ficción, mientras que el arte vitaliza la vida y se instala en la ficción en cuanto tal, en la posibilidad de crear continuamente sus puntos de vista. Sus ideales o ficciones son sus mismos objetos, por principio plásticamente infinitos. Sin embargo, el arte, por otra parte, no es búsqueda del sentido de la vida; no formula preguntas radicales exigiendo que la vida misma responda a ellas y forje una teoría general del vivir. Este sería más bien, propiamente, un esfuerzo filosófico. A pesar de ello, las creaciones artísticas se mueven en la perspectiva de la vida, crean posibilidades concretas suyas y nos introducen al ob-jeto de la vida misma, a lo que ella pro-yecta como totalidad inagotable en su perspectiva. El arte nos introduce a la razón de la vida, a su proyecto, que es la humanidad o "el hombre" que se revela en cada hombre, en cada individuo. El artista crea un "estilo", crea modos de ser humanos, y, por tanto, mundos.

En definitiva, el precipitado del arte revela el objeto inagotable del arte supremo de la vida: el hombre que cada uno va siendo en su vida como interpretación del hombre en general. "El artista", "el científico", "el filósofo", son posibilidades de la vida, creaciones de humanidad. De hecho, Ortega sostendrá siempre que la vida es "faena poética", forma suprema de arte, porque me obliga a ser escritor a la vez que autor de mí. Y tal es la razón de la apertura temporal de mi vida: proyecto personal, forzosa libertad de anticipar quien voy a ser como recreación presente de quien he sido.

La razón vital, concluimos, no puede revelarse al pensamiento filosófico que se atiene a la idea clásica de verdad como adecuación del intelecto a las cosas, sea cual sea su derivación -incluso fenomenológica, que desde la intencionalidad activa o pasiva busca la trascendencia en la inmanencia-. La razón como adecuación a lo dado lleva a desatender la función vital de las ideas y del pensamiento, que genuinamente responden al esfuerzo por saber a qué atenerme respecto de quien soy, alumbrando a la vez necesidades y posibilidades vitales. "El ser" es un ideal, un punto de vista o ficción que se sustituye a la conceptuación espontánea de la vida para que podamos adecuarnos a ella, clausurando su totalidad, como bien vio por su parte Levinas en Totalité et infini. El ob-jectum de la vida, la que la constituye su pro-yecto, eso es, la razón de la apertura de su perspectiva temporal como espacialización antropomórfica, soy "yo". No puedo adecuarme a mi yo, sino solo proyectarlo creadoramente; mi vida es, en este sentido, inadecuada consigo misma. Perspectiva es proyecto, "quien", inadecuación del presente consigo mismo, creación de tiempo, de quien voy a ser en vista de quien he sido, potencia de realización circunstancial, fuente de sistematicidad de toda estructura.

Y tal es la razón última, como hemos ido concluyendo en el cuarto apartado, por la que la vida, proyectivamente abierta por y para la comprensión de mí en vista de un tú, - "personalización de la circunstancia en mundo" $\neg$, según expresión de Ortega - tenga una estructura empírica antropomórfica. La procedencia metafísica personal de tal estructura empírica la diferencia de otros descubrimientos análogos 
de la filosofía contemporánea, como el das Man de Heidegger o el togetherness de Gabriel Marcel. Hemos recordado, finalmente, como hemos hecho en otros escritos, que también la idea de la "estructura empírica de la vida humana" de Marías cuenta con un importante antecedente teórico orteguiano: el concepto de "nostridad" presente en su obra póstuma El hombre y la gente (1956), cuya exposición Marías llego seguramente a conocer anteriormente, en el Instituto de humanidades (1948). El hombre y la gente de Ortega y La estructura social (1955) de Marías son frutos de aquella colaboración ${ }^{80}$.

He aquí, como indica el título de este trabajo, la mereología, la epistemología y la metafísica de Ortega como fundamento de la Antropología Metafísica de Marías.

\section{Referencias bibliográficas}

Cerezo Galán, P.: La voluntad de Aventura. Aproximación crítico al pensamiento de Ortega y Gasset, Ariel, Barcelona, 1984.

De Nigris, F.: Libertad y Método. El liberalismo desde la perspectiva personal de Ortega y Marías. Editorial FUE. Madrid, 2005 (Introducción de Julián Marías).

De Nigris, F.: “La razón vital de Ortega y la analítica existencial de Heidegger." Ideas y Valores, Vol. 61, n.148.

De Nigris, F.: "Intencionalidad, pasividad y autoconciencia en la fenomenología de Husserl”, Ideas y Valores, LXIV, nº 157, Universidad Nacional de Colombia, abril de 2015.

De Nigris, F.: "Ortega et la métaphysique", Revue Internationale de Philosophie, 1/2015, Vrin, Paris.

Ferrater Mora, J.: Ortega y Gasset, Editorial Seix Barral, Barcelona, 1958.

Heidegger, M.: en Sein und Zeit (Max Niemeyer Verlag, Tübingen, 1967.

Marcel, G.: Homo Viator, Aubier, Éditions Montaigne, Paris, 1944.

Marías, J.: Historia de la filosofía, Obras, I, Revista de Occidente, Madrid, 1982.

Marías, J.: Introducción a la filosofía, Revista de Occidente, Obras II, Madrid, 1982.

Marías, J.: Ortega. Circunstancia y vocación, Obras IX, Revista de Occidente, 1982, p.557.

Marías, J.: Antropología metafísica, Alianza Editorial, Madrid, 1983.

J. Ortega y Gasset, Obras Completas, Taurus, Madrid, vol. I-X, 2004-2010.

J. Ortega y Gasset, Meditaciones del Quijote, ed. Cátedra, Madrid, 1984.

Rodríguez Huéscar, A.: Perspectiva y verdad, Revista de Occidente, Madrid, 1966.

Zubiri, X.: Sobre la esencias, Alianza Editorial, Sociedad de Estudios y Publicaciones, Madrid, 1985.

Realitas III-IV 1976-1979, Trabajos de Seminario Xavier Zubiri, Sociedad de estudios y Publicaciones, Madrid, 1979.

${ }^{80}$ Cf. F. de Nigris, Libertad y Método. El liberalismo desde la perspectiva personal de Ortega y Marías, op. cit., capítulos X, XI. 